\title{
ANATOMIA FUNCIONAL DE PERNA PERNA (LINNÉ) (BIVALVIA, MYTILIDAE)
}

\author{
Walter Narchi ${ }^{1}$ \\ Mario Sergio Galvão-Bueno ${ }^{2}$
}

\begin{abstract}
Functional anatomy of PERNa PERNa (Linné) (Bivalvia, Mytilidae). Perna perna (Linné, 1758) occurs on the Atlantic littoral from Venezuela to Uruguay. The main organ systems were studied in the living animals, particular attention being paid to the ciliary feeding and cleansing mechanisms in the mantle cavity. The anatomy, functioning of the stomach and the ciliary sorting mechanisms are described. The siphons belong to type A (YONGE 1948b), the ctenidia to type B(1) (ATKINS 1936c) and the stomach is of type III (PURCHON 1957) or Section I (DINAMANI 1967) with sorting mecanisms of type A and B (REID 1965). A general comparison was made between the genera of the Mytilidae known and some features of Mytella Soot-Ryen, 1955.

KEY WORDS. Bivalvia, Mytilidae, Perna perna, functional anatomy, Brazilian littoral
\end{abstract}

De acordo com Soot-Ryen (1955), a família Mytilidae compreende 23 gêneros, dos quais KLAPPENBACH (1964) registrou apenas $12 \mathrm{em}$ águas brasileiras: Mytilus Linné, 1758, Perna Retzius, 1788, Brachidontes Swainson, 1840, Mytella Soot-Ryen, 1955, Modiolus Lamarck, 1799, Amygdalum Megerle von Mühlfeld, 1811, Lioberus Dahl, 1898, Musculus Röding, 1789, Gregariella Monterosato, 1884, Crenella Brown, 1827, Botula Mörch, 1853 e Lithophaga Röding, 1798. O gênero Perna foi criado por Retzius em 1788 na "Dissertatio historico-naturalis nova Testaceorum genera" (SOOT-RYEN 1955), com o tipo Perna magellanica Retzius, 1788, já descrito em 1758 por Linné como Mya perna (KLAPPENBACH 1965). O gênero foi revalidado, em 1955, por SOOT-RYEN (1955), por ser o nome mais antigo para o grupo de mitilídeos incluídos comumente no gênero Chloromya Mörch, 1853. O gênero, segundo SiDALL (1980), caracteriza-se pela concha lisa, borda resilial perfurada, duas cicatrizes de músculos retratores do pé, usualmente dois (às vezes um) dentes dissodontes, dez a dezoito dentes primários laterais e ausência do músculo adutor anterior.

A espécie $P$. perna foi descrita por Linné, em 1758, na décima edição do "Systema Naturae", com o nome de Mya perna. Na sinonímia estão, entre outros, Mytilus elongatus Chemnitz, 1785, Perna magellanica Retzius, 1788, Mytilus magellanicus Röding, 1788 e Mytilus (Chloromya) perna (Linné, 1758).

1) Departamento de Zoologia, Instituto de Biociências, Universidade de São Paulo. Caixa Postal 11461, 05422-970 São Paulo, São Paulo, Brasil.

2) Departamento de Biociências, Universidade de Guarulhos. 07023-070 Guarulhos, São Paulo, Brasil. 
Da mesma forma, Mytilus achatinus Lamarck, 1819 (LAMY 1920) e Mytilus elongatus Metivier, 1967 (Rios 1994) devem ser consideradas como sinônimos de Perna perna (Linné, 1758).

SIDDALL (1980) tentou fazer uma revisão histórica e esclarecer o posicionamento do gênero Perna, mostrando quão confuso é o status taxonômico das espécies dentre os Mytilidae. Para MORTON (1987), como o autor precedente, o gênero Perna é representado por três espécies com distribuição geográfica sem recobrimento: $P$. canaliculus (Gmelin, 1791) restrito a Nova Zelândia, $P$. viridis (Linné, 1758) do Indo-Pacífico, e $P$. perna que é amplamente distribuída ao longo das costas da África e da costa atlântica da América do Sul.

Perna perna vive na costa oeste do Atlântico desde a Ilha Margarita e Cumaná (Venezuela) até a Ilha de Lobos e Punta del Este (Uruguai), sendo abundante entre Rio de Janeiro e Santa Catarina (KLAPPENBACH 1964; BEAUPERTHUY 1967a). Segundo LANGE DE MORRETES (1949) a espécie ocorre no Rio de Janeiro, Santos (São Paulo), Paraná e Santa Catarina. Para KLAPPENBACH (1965), esta espécie constitui o maior mitilídio brasileiro. Rios (1994) registrou seu aparecimento na Venezuela, toda a costa do Brasil até o Uruguai; duvida de sua ocorrência em Mar del Plata, Argentina, e assinalou seu aparecimento na África do Sul.

A espécie foi descrita originalmente para o Estreito de Magalhães, localização considerada errada por KLAPPENBACH (1964). Parece que sua distribuição não se extende para o sul, além do Uruguai, onde é confirmada por BARATTINI \& URETA (1961). A espécie não é citada para a região patagônica nos catálogos de CARCELLES (1944, 1950), CARCElles \& Williamson (1951) e Ageitos de Castellanos (1957). Para SidDALL 1980, registros do aparecimento de P. perna em águas frias ao sul do Rio da Prata, Argentina, até o Estreito de Magalhães, constituem pontos a serem discutidos. Também não há referências para essa espécie na costa pacífica pois, segundo BEAUPERTHUY (1967b) não ocorre no litoral do Chile.

Curiosamente, BEAPERTHUY (1967b) estende sua distribuição às costas da África e da Ásia Central, devido a ampliação da sinonímia, o que pode ter acontecido com BERRY (1978) e LUBET (1973).

Perna perna é molusco de importância alimentar nas regiões onde ele ocorre em grande quantidade, ou seja, entre os estados do Rio de Janeiro e Santa Catarina (IHERING 1900). Essa espécie foi estudada sob vários aspectos. SAWAYA \& ABBUD (1963) estudaram a farmacologia do músculo adutor, trabalho continuado por ABBUD (1969). A fisiologia e a farmacologia do coração foi objeto de pesquisa por SAWAYA \& KHOURI $(1963,1965)$ e SAWAYA \& Oliveira (1965). LAVALlaRD et al. (1969) pesquisaram o crescimento relativo da concha. Sem dúvida nenhuma, os aspectos da reprodução e desenvolvimento da espécie mereceram a atenção de muitos autores. BOUCART et al. (1965), discutiram a ultra estrutura do espermatozóide. RoJAS (1967) e ROJAS \& MARTINEZ (1967) pesquisaram os aspectos da biologia principalmente a reprodução e desenvolvimento larval experimental da espécie. EPIFANIO (1967) identificou e descreveu as larvas do mexilhão do litoral da Venezuela. UMIJI (1969) estudou a neurosecreção e sua correlação com o ciclo reprodutivo do animal. ROMERO (1980) verificou os efeitos da salinidade e temperatura sobre embriões e larvas de $P$. perna. LUNETTA (1969) e CARMO \& LUNETTA 
(1978) desenvolveram estudos relativos ao ciclo reprodutivo de $P$. perna. BERRY (1978) efetuou estudos sobre a reprodução, crescimento e produtividade da espécie da costa africana. MAGALHÃES (1985) determinou o teor de proteína em função do ciclo sexual.

No que se refere à mitilicultura no litoral brasileiro, SAWAYA (1965) já estudara as possibilidades da criação de $P$. perna no litoral do estado de São Paulo e atualmente vários pesquisadores ou mesmo pequenas empresas tem feito com sucesso bancos de criação no litoral de São Paulo e Santa Catarina. Entre nós, FERREIRA et al. (1990) desenvolveram pesquisas para o cultivo de mexilhões.

Com relação aos estudos sobre fisiologia, ressalta-se os seguintes trabalhos: DIONI (1963) analisou o consumo do oxigênio da espécie; HIROKI (1977) verificou o efeito da baixa concentração de oxigênio e da presença de sulfeto de hidrogênio sobre o batimento ciliar nos ctenídios de $P$. perna; SALOMÃo et al. (1980) e SALOMÃo \& LUNETTA (1989) estudaram a influência da salinidade na sobrevivência da espécie; ZuIM \& MENDES (1980a,b, 1981) compararam a tolerância de $P$. perna e Brachidontes solisianus (Orbigny, 1846) a diferentes situações de salinidade do meio em que os animais vivem assim como quando submetidos a diferentes concentrações de detergente iônico; STUCCHI-ZUCCHI \& SALOMÃo (1992) estudaram o efeito osmo-iônico no conectivo cérebro-visceral de Perna perna.

Da família Mytilidae, apenas alguns gêneros foram estudados sob o ponto de vista da anatomia funcional, entre os quais destaca-se o gênero Mytilus, a espécie Brachidontes darwinianus darwinianus (Orbigny, 1846) por AVELAR \& NARCHI (1984) e Mytella charruana (Orbigny, 1846) por NARCHI \& GALVÃO-BUENO (1983).

No entanto, nenhum estudo da anatomia funcional desse mitilídeo havia sido levado a efeito, nada se conhecendo com relação às adaptações dos animais ao meio em que vivem. Este trabalho procurou evidenciar as adaptações anátomo-funcionais dessa espécie ao meio em que vive.

\section{MATERIAL E MÉTODOS}

Os espécimes de $P$. perna ocorrem comumente no litoral de São Paulo em substrato rochoso e foram coletados na baía de São Vicente, no litoral do estado de São Paulo, num conglomerado de rochas granito-gnaissica, situado a noroeste da Ilha Porchat (235' $\left.12^{\prime \prime S ~ e ~} 46^{\circ} 22^{\prime} 22^{\prime \prime W}\right)$. Nesse substrato ocorrem junto com Brachidontes solisianus, cracas e outros animais. Perna perna extende-se desde a faixa exposta pelas marés baixas (médio e infralitoral) até níveis superiores na face da rocha não protegida dos impactos das ondas. Os animais foram coletados arrancando-os da rocha onde se prendem fortemente pelo bisso.

Perna perna tem um tamanho médio de $5-8 \mathrm{~cm}$ de comprimento por $3-4 \mathrm{~cm}$ de largura e $2-3 \mathrm{~cm}$ de espessura. É o maior dos mitilídeos brasileiros, podendo atingir até $14 \mathrm{~cm}$ de comprimento (KLAPPENBACH 1964). Os espécimes são mitiliformes, porém mais encorpados que Mytella charruana (NARCHI \& GALVÃO-BUENO 1983), tendo o ângulo dorsal em posição mais mediana, e sua cor é castanha pouco mais escura. Todos os exemplares analisados tinham a mesma coloração. 
Os animais foram mantidos vivos em aquários colocados em ambiente com temperatura constante $\left(20^{\circ} \mathrm{C}\right)$ por períodos de até 30 dias. Foram utilizados animais vivos, anestesiados e posteriormente fixados em álcool ou formol.

Desenhos foram feitos observando-se animais vivos ou animais fixados; aos detalhes de anatomia adicionou-se, posteriormente, indicações funcionais, tais como correntes ciliares. Estas foram visualizadas pela movimentação de partículas em suspensão de carmim, de aquadag (grafite coloidal) e carborundum bem fino, a medida que precipitavam sobre os órgãos e estruturas. A utilização de aquadag e de carborundum, técnica já usada por ATKINS (1936a), NARCHI (1972 e 1974b) e HEBLING (1976), visa eliminar as dificuldades apontadas por KELLOGG (1915) com o uso do carmim, que, muito leve, permanece em suspensão na água, sendo carregado por ela e não pelos cílios. Dissecções foram processadas pelas técnicas usuais. Cortes seriados de $10 \mu \mathrm{m}$ foram feitos em animais fixados em Bouin e incluidos em parafina. A coloração foi feita pelo processo tradicional da hematoxilina e eosina.

Animais fixados em álcool ou formol foram previamente anestesiados com cloreto de magnésio, para evitar retração, como fizeram HEBLING (1976), NARCHI (1972) e AVELAR \& NARCHI (1984).

Os ctenídios foram examinados em animais vivos, em água do mar, e as correntes ciliares observadas com a adição de carborundum em pó, aquadag e carmim, segundo a metodologia de RIDEWOOD (1903), ATKINS (1936c), NARCHI (1972) e HEBLING (1976).

Os palpos foram estudados sob microscópio estereoscópico, sob água do mar, usando-se carmim e carborundum em pó para a evidenciação das correntes ciliares, técnica já usada por NARCHI (1974a). Para evidenciar as correntes entre as pregas que permanecem encostadas umas às outras, os palpos foram dobrados de várias maneiras.

Para o estudo do canal alimentar foram feitas dissecções, sob microscópio estereoscópico, em animais fixados em álcool ou formol e em animais vivos. Cortes transversais, espessos, de 0,5 a $1 \mathrm{~cm}$ de espessura, foram feitos e desenhados. Completou-se o estudo com cortes seriados de animais totais ( $10 \mu \mathrm{m}$ de espessura), seguidos de reconstituição gráfica.

As observações de espécimes vivos foram realizadas nos próprios locais de coleta e os trabalhos de laboratório, no Departamento de Zoologia do Instituto de Biociências da Universidade de São Paulo, onde foram mantidos vivos e em boas condições por algum tempo.

\section{RESULTADOS}

\section{Valvas da Concha}

A concha dos mitilídeos é equivalva e inequilateral, com umbos prosógiros próximos à extremidade anterior (SOOT-RYEN 1955).

A concha da espécie aqui estudada é equivalva e inequilateral, mitiliforme, com um ângulo suave no lado dorsal, borda posterior arredondada e lado ventral 
côncavo (Fig. 1). Foi verificado para Perna perna o mesmo fato já apontado por WHITE (1937) para Mytilus edulis Linné, 1758, ou seja, a tendência que a concavidade da borda ventral das valvas tem em ser maior nos animais que vivem em costões expostos do que naqueles de costões protegidos. Nestes, a borda ventral torna-se mais convexa.
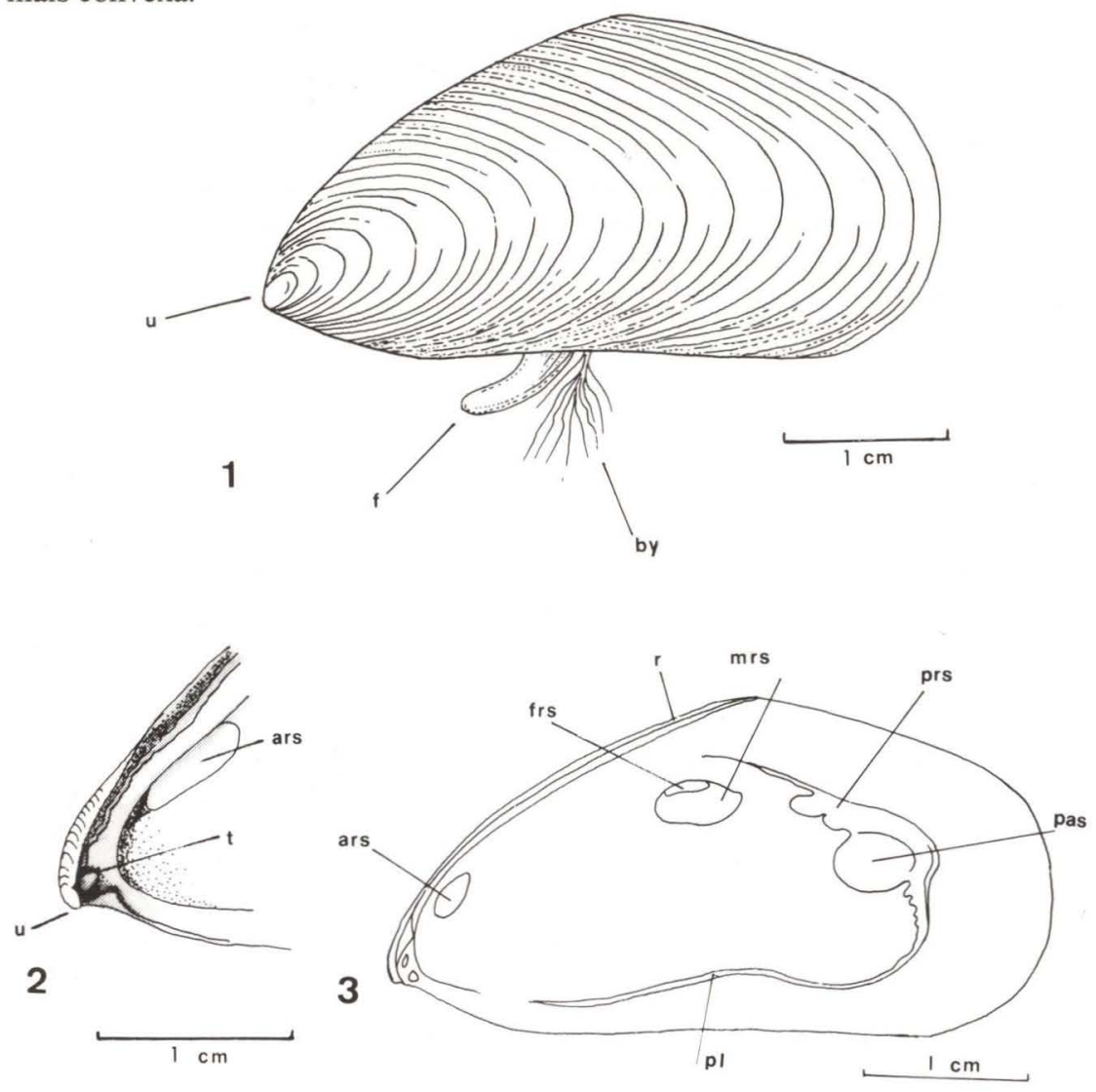

Figs 1-3. Perna perna. (1) Aspecto externo da concha, vista pelo lado esquerdo; (2) detalhe da região umbonal interna da valva direita; (3) face interna da valva direita. (ars) Cicatriz do músculo anterior retrator do bisso, (by) bisso, (f) pé, (frs) cicatriz do músculo retrator do pé, (mrs) cicatriz do músculo mediano retrator do bisso, (pas) cicatriz do músculo adutor posterior, (pl) cicatriz do músculo palial, (prs) cicatriz do músculo posterior retrator do bisso, (r) resílio, (t) dente, (u) umbo.

$\mathrm{O}$ ângulo dorsal em $P$. perna situa-se na metade do comprimento do animal. Ao estudar a condição heteromiária, YONGE (1953) concluiu que a fixação através do bisso fez com que o pé se tornasse um ponto ventral de fixação levando a alterações na forma do corpo com o conseqüente deslocamento dos umbos e do ligamento para a região anterior. Com isso, a região dorsal foi a mais afetada, tendo 
o músculo adutor anterior diminuido sensivelmente, o que levou os animais da condição heteromiária à monomiária. Essa afirmação foi confirmada no presente estudo.

Os umbos são terminais em $P$. perna e BEAUPERTHUY (1967b) considera o perióstraco dessa espécie espesso, além de citar cores variadas.

A coloração verde foi citada por SOOT-RYEN (1955) para o gênero Perna e na descrição original de Linné, este autor mencionou "violeta mesclada com púrpura e ágata" (SOOT-RYEN 1955). SANTOS (1955) descreveu a espécie $P$. perna com cor "avermelhada parda ou, às vezes, verde munida de estrias irregulares angulosas, às vezes, obsoletas". Já para BEAUPERTHUY (1967b) a variação de cor vai desde o amarelo, verde, marrom avermelhado e marrom escuro, chegando a verificar "belos reflexos azuis ao ser observado dentro d'água", como também manchas em "zigzag".

Dos animais estudados, apenas alguns exemplares de $P$. perna apresentavam em sua parte posterior uma leve tonalidade esverdeada sob o castanho.

Em $P$. perna as linhas concêntricas de crescimento centram-se no ápice da valva, já que o umbo é apical, quase não existindo lúnula, que é muito reduzida, praticamente inexistente.

A lúnula é, nos mitilídeos, sempre limitada por dentes dissodontes na sua margem interna (SOOT-RYEN 1955). Em P. perna não foi evidenciada nenhuma saliência dorsal, mas sim um a dois dentes no lado ventral (Fig. 2), sendo mais comum apenas um único dente. A constatação da variação do número de dentes, nesta espécie, confirma o trabalho de BEAUPERTHUY (1967b). Quando existiam dois dentes, o mais ventral era de tamanho reduzido. WHITE (1937) prefere denominar essas estruturas de denticulações, baseando-se, principalmente, na sua inconstância em tamanho e número, pois em Mytilus edulis, por ele estudado, os dentes variavam de 1 a 6 . No lado dorsal, desde o umbo até o ângulo dorsal, extende-se a borda resilial, de cor branca, apresentando uma série de escavações pequenas fortemente marcadas. Sob a borda resilial insere-se o ligamento elástico, de cor castanho-escura. $\mathrm{O}$ perióstraco estende-se além e por cima do ligamento elástico.

A face interna das valvas é esbranquiçada e nacarada, tendo várias cicatrizes musculares. Na porção anterior dorsal existe uma cicatriz correspondente ao músculo retrator anterior do bisso (Fig. 3), elíptica em P. perna sendo assim semelhante a de Mytilus edulis, também elíptica (SOOT-RYEN 1955), embora aqui seja claramente bilobada (WHITE 1937), o que não acontece em $P$. perna. Ainda na região anterior, duas características específicas são notadas. Na valva de $P$. perna não existe a cicatriz do músculo adutor anterior, pois esse músculo não ocorre. Esta ausência é uma das características distintivas do gênero Perna; todos os outros mitilídeos (incluindo Mytilus) a possui, se bem que sempre reduzida (SOOT-RYEN 1955).

Todos os outros músculos que se inserem nas valvas de $P$. perna apresentam-se de forma a marcar dois grupos distintos de cicatrizes. Em Mytilus formam uma única cicatriz (WHITE 1937). Na região mediana do músculo retrator do bisso, encontrou-se uma cicatriz pequena, dorsal, correspondente à inserção do músculo 
retrator do pé (Fig. 3, frs), maior em P. perna que do que em Mytella charruana, observada por NARCHI \& GALVÃO-BUENO (1983). Essa cicatriz conflue com a do músculo retrator mediano do bisso (mrs), aproximadamente circular e concentrada em $P$. perna, e alongada e estendendo-se para a parte posterior em Mytella charruana.

A cicatriz do músculo retrator posterior do bisso (Fig. 3, prs) se continua com a cicatriz arredondada do músculo adutor posterior. Deste parte uma cicatriz alongada que percorre a parte posterior e a parte ventral da valva, pertencente ao músculo da margem do manto, que apresenta uma leve reentrância para o centro da valva na região do pé, simulando um seio palial muito incipiente.

Os sifões não têm nenhum efeito sobre o ligamento. Como nos outros Mytilacea (YONGE 1957), as extensões periostracais do ligamento dessa espécie parecem ter significado funcional, provavemente devido à redução dos dentes. A extensão periostracal posterior já havia sido observada em Modiolus, Lithophaga e Botula por YONGE (1955), em Brachidontes darwinianus darwinianus por AVELAR \& NARCHI (1984) e em Mytilus por YoNGE (1957). TRUEMAN (1950), que também estudou esse último gênero, denominou a extensão periostracal posterior de "coberta posterior".

\section{Sifões}

Os sifões são formados pela fusão das dobras do manto ou mesmo pelo próprio manto. Foram classificados por Yonge de acordo com o tipo de fusão e as partes do manto envolvidas. Os sifões de $P$. perna classificam-se como do tipo A (YONGE 1948b), onde somente a dobra interna, muscular, está envolvida; a abertura exalante conserva o caráter primitivo e não constitui um verdadeiro sifăo, é assim formada, conservando o caráter primitivo. A margem ventral do sifão inalante é formada pela justaposição das margens do manto. Sua abertura se continua pela abertura do pé, o que é característico em Mytilidae, até mesmo nos gêneros que possuem sifões longos, como em Lithophaga (YONGE 1955) e em Botula (FANKBONER 1971).

Os sifões sendo formados pela prega interna não apresentam tentáculos, embora na borda da abertura inalante exista uma série de lóbulos tentaculares, como nos Tellinacea, cujo sifão também é desse tipo (YONGE 1957).

O sifão exalante é completo, como em todos os Mytilidae (YONGE 1955), e formado apenas por uma projeção do manto ao redor do orifício exalante (Figs. 4-5). YONGE (1948b) considera-o mais como abertura do que como sifão verdadeiro. Sua margem é simples, sem papilas ou tentáculos, e a abertura é bem menor do que a do inalante.

O sifão inalante tem sua abertura continuando-se pela abertura do pé. As margens do sifão inalante são lobuladas e na região ventral se justapõem, completando o sifão. Sua borda é densamente frangeada, apresentando, de cada lado, seis espessamentos na superfície interna. Quando o sifão se fecha, esses espessamentos se encaixam como dentes de uma engrenagem. A margem é pregueada com lóbulos tentaculares curtos, digitiformes, pouco maiores em P. perna que em Mytella charruana, como descritos por NARCHI \& GALVÃO-BUENO (1983), se bem que esta 
última espécie projete seu sifão mais para fora que aquela espécie. Assim que o sifão se abre, as papilas voltam-se para a região interna da abertura restringindo o seu tamanho. Quando os animais eram colocados em água limpa e estavam em completo repouso, o sifão se distendia totalmente e as papilas voltavam-se para o exterior, aumentando a abertura. O mesmo fato foi também observado por AVELAR \& NARCHI (1984) em Brachidontes darwinianus darwinianus e por NARCHI \& GALVÃo-BUENo (1983) em Mytella charruana. As papilas são maiores e ramificadas nos espessamentos e menores e simples entre eles.

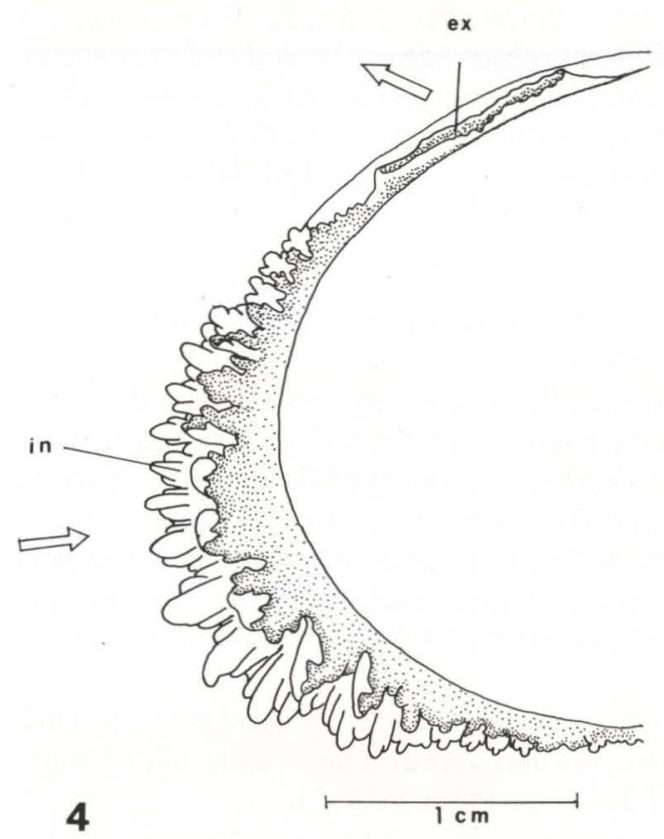

5

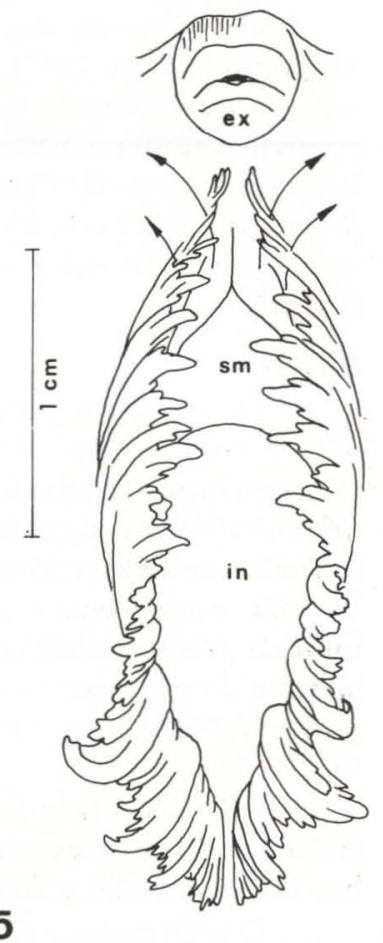

Figs 4-5. Perna perna, sifões exalante e inalante. (4) Vistos pelo lado direito do animal; (5) vistos pela região posterior do animal. A pigmentação da face interna dos sifões não está representada. (ex) sifão exalante, (in) sifão inalante, (sm) membrana sifonal.

A abertura do sifão inalante é separada da do sifão exalante por uma lâmina triangular que, distendendo-se ou contraindo-se, pode também aumentar ou reduzir essa abertura. KELLOGG (1915) a descreveu em Mytilus edulis e Mytilus californianus Conrad, 1837, e a denominou de membrana branquial, o que foi confirmado por WHITE (1937) para aquela espécie. ORTON (1912) já a observara neste gênero, chamando-a de "cortina". Ocorre ainda em Brachidontes darwinianus darwinianus segundo AVELAR \& NARCHI (1984). Aparece também em espécies dos gêneros 
Schizothaerus Conrad, 1853, Mactra Linné, 1767, e Spisula Gray, 1837 nos Mactracea (KeLlOGG 1915; YoNGE 1948a), bem como em espécies dos gêneros Tivela Link, 1807 (Kellogg 1915; NARCHI 1972) e Anomalocardia Schumacher, 1817, nos Veneracea NARCHI (1972). YoNGE (1948a, 1955) denominou-a de membrana valvular sifonal, termo também adotado por NARCHI (1972). HEBLING (1976) usou a denominação diafragma ao descrevê-la em espécies do gênero Anodontites Bruguière, 1792, reservando o termo membrana sifonal para a borda do sifão.

A entrada de partículas na cavidade palial é facilitada pela grande abertura do sifão inalante e pelo fato das papilas, principalmente as da região ventral, voltarem-se para o exterior quando o sifão está totalmente aberto.

Entre o limite superior e o primeiro espessamento do sifão inalante ocorre, de cada lado, um sulco de rejeição (Fig. 5). Tanto a superfície interna quanto a externa desse sifão são de cor castanha bastante escura que se extende até a sua borda.

Em Botula falcata Gould, 1851, pequenas manchas esparsas foram relacionadas por YONGE (1955) provavelmente com o grau de exposição à luz. Essa espécie vive em túneis que cava em rochas, não se expondo à luz. $\mathrm{O}$ mesmo acontece em Mytella charruana, que se enterra no lodo (NARCHI \& GALVÃO-BUENO 1983). De forma diferente, $P$. perna já se expõe à luz por viver sobre substrato rochoso exposto ao sol.

A sensibilidade dos sifões é muito grande em $P$. perna. À menor trepidação ou um escurecimento brusco, mas leve, como colocar a mão sobre a cuba onde se encontrava o animal, era suficiente para que os indivíduos retraíssem seus sifões. O mesmo fato já havia sido observado para outras espécies por OWEN (1953), NARCHI (1972), AVELAR \& NARCHI (1984) e NARCHI \& GALVÃo-BUENO (1983). Essa grande sensibilidade dos sifões foi associada por NARCHI (1972) à vida em águas calmas.

\section{Borda do Manto}

Em Perna perna a borda do manto é lisa, sem fusões, totalmente livre ao longo da abertura pediosa e se apresenta com três dobras. A dobra externa forma a concha, sendo o perióstraco secretado na goteira periostracal, entre a dobra externa e a média (YONGE 1957). O estudo histológico, em Mytilus edulis, indica que o perióstraco é secretado pelo epitélio da dobra externa e não pela dobra mediana (BEEDHAM 1958). A dobra média tem função sensorial. A dobra interna é caracteristicamente muscular (YONGE 1948b).

Os lobos médio e externo são contínuos ao redor de toda a margem da valva, inclusive na região posterior onde os dois lobos musculares se unem para formar o sifão. Como acontece em Lithophaga (YONGE 1955), esses dois lobos, na espécie aqui estudada, fundem-se na região anterior para constituir uma estreita ponte de tecido que delimita anteriormente a abertura do pé, que é ventral.

\section{Musculatura}

A musculatura de $P$. perna já foi descrita em linhas gerais por ABBUD (1969) e comparada com a de Mytilus edulis, relatada por WHITE (1937). 
Considera-se, geralmente, três tipos de músculos extrínsecos: músculos adutores, músculos do bisso e músculos do pé. Entre os músculos intrínsecos, o músculo marginal do manto é o mais importante.

\section{Músculos Adutores}

O gênero Perna é caracterizado, segundo SidDaLl (1980) nos animais jovens e adultos, e segundo Rios (1994) nos animais adultos, pela ausência total do músculo adutor anterior (Fig. 6). Em P. perna foi encontrado apenas o músculo adutor posterior (pam), cuja localização, seção e tamanho são semelhantes aos do adutor posterior de Mytella charruana (NARCHI \& GALVÃO-BUENO 1983). Perna atinge, então, a condição monomiária, que ocorre entre os mitilídios nesse gênero (SOOT-RYEN 1955) e, de acordo com SidDALl (1980) em Chloromytilus Soot-Ryen, 1952 e Perna.

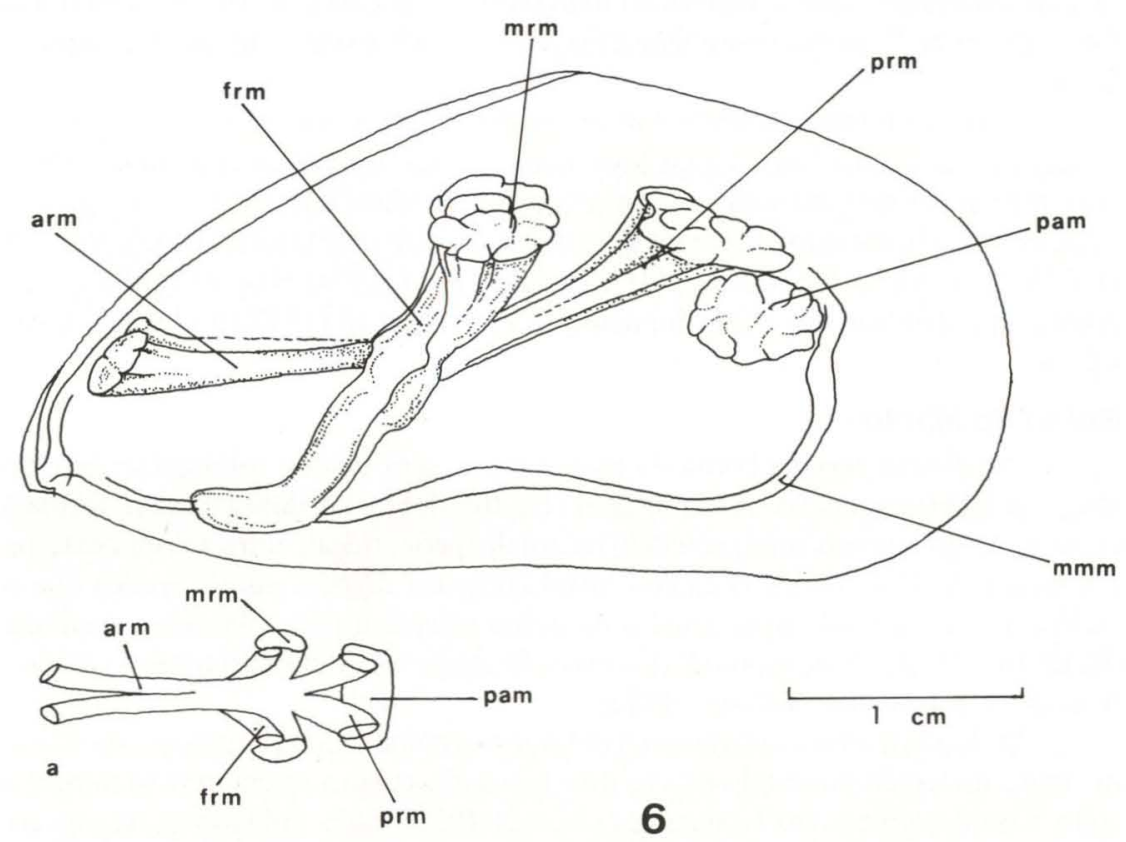

Fig. 6. Perna perna, musculatura em vista lateral esquerda. (a) vista dorsal semi esquemática, (arm) músculo anterior retrator do bisso, (frm) músculo retrator do pé, $(\mathbf{m m m})$ músculo marginal do manto, (mrm) músculo mediano retrator do bisso, (pam) músculo adutor posterior, (prm) músculo posterior retrator do bisso. 


\section{Músculos do Bisso}

Existem três pares de músculos retratores do bisso: um anterior, um mediano e um posterior (Fig. 6). Em P. perna, como em Mytella charruana, o padrão de constituição desses músculos é o mesmo, mas em $P$. perna eles são muito mais desenvolvidos do que em $M$. charruana, relacionando-se, portanto, ao hábito daquela espécie, onde os indivíduos se fixam fortemente pelo bisso às rochas.

Os músculos anteriores retratores do bisso (Fig. 6, arm) são longos e delgados, inserindo-se na região dorsal anterior, um na valva direita e outro na esquerda, fora da cavidade umbonal. Unem-se ao passar por entre os músculos retratores do pé (frm), terminando na glândula do bisso. A sua inserção valvar é dorsal e maior em $P$. perna do que em M. charruana (NARCHI \& GALVÃO-BUENO 1983).

Os músculos medianos retratores do bisso $(\mathrm{mrm})$ são mais curtos e espessos que os anteriores. Inserem-se ventralmente ao resílio, abaixo do ângulo dorsal da valva, juntamente com os músculos retratores do pé (frm).

Os músculos posteriores retratores do bisso (prm), longos e de espessura semelhante à dos músculos medianos, fixam-se acima da inserção do músculo adutor posterior. Em $P$. perna sua inserção não une as cicatrizes do músculo mediano retrator do bisso $(\mathrm{mrm})$ e a do músculo adutor posterior (pam) de cada lado. Em M. charruana (NARCHI \& GALVÃO-BUENO 1983) ocorre formando essa união uma cicatriz contínua.

\section{Músculos do Pé}

No pé existem dois músculos retratores, que se inserem na região dorsal da concha, contígua e internamente à inserção dos músculos retratores medianos do bisso. São os músculos retratores do pé (Fig. 6, frm). Cada músculo é estreito, com sua parte distal paralela ao músculo retrator mediano do bisso $(\mathrm{mrm})$, enquanto sua parte proximal contorna os músculos retratores anteriores do bisso (arm) e, com outras fibras musculares e outros tecidos, forma o pé.

\section{Músculo Marginal do Manto}

Entre os músculos intrínsecos ressalta-se o músculo marginal do manto (Fig. 6, mmm), que se estende desde o músculo adutor posterior (pam) até a região anterior do animal, chegando até o músculo adutor anterior (aam). Percorre toda a borda do manto e, na porção ventral do animal, apresenta uma leve concavidade mediana. Na região posterior, próximo e ventral ao músculo adutor posterior (pam), é forte, correspondente à região do sifão inalante, de maior motilidade.

Este músculo é constituído por fibras radiais que se inserem na valva ao longo da linha palial e por fibras longitudinais entre as radiais. A motilidade da margem do manto é conseqüência da ação desses músculos e também da pressão do sangue nas lacunas aí existentes.

\section{Pé e bisso}

O pé é um órgão cilíndrico, densamente musculoso e achatado na região ventral, onde apresenta uma série de dobras rasas, paralelas entre si e de disposição transversal (Fig. 7). Nessa face localiza-se longitudinalmente o sulco do bisso (bg), 
que termina numa pequena cavidade próxima ao ápice do pé. O sulco tem início na abertura da glândula bissogênica, que está situada na porção proximal do pé, é profundo (Fig. 7), sendo ainda ladeado por um par de dobras formando a proteção ao sulco que não existe próximo à sua extremidade distal.
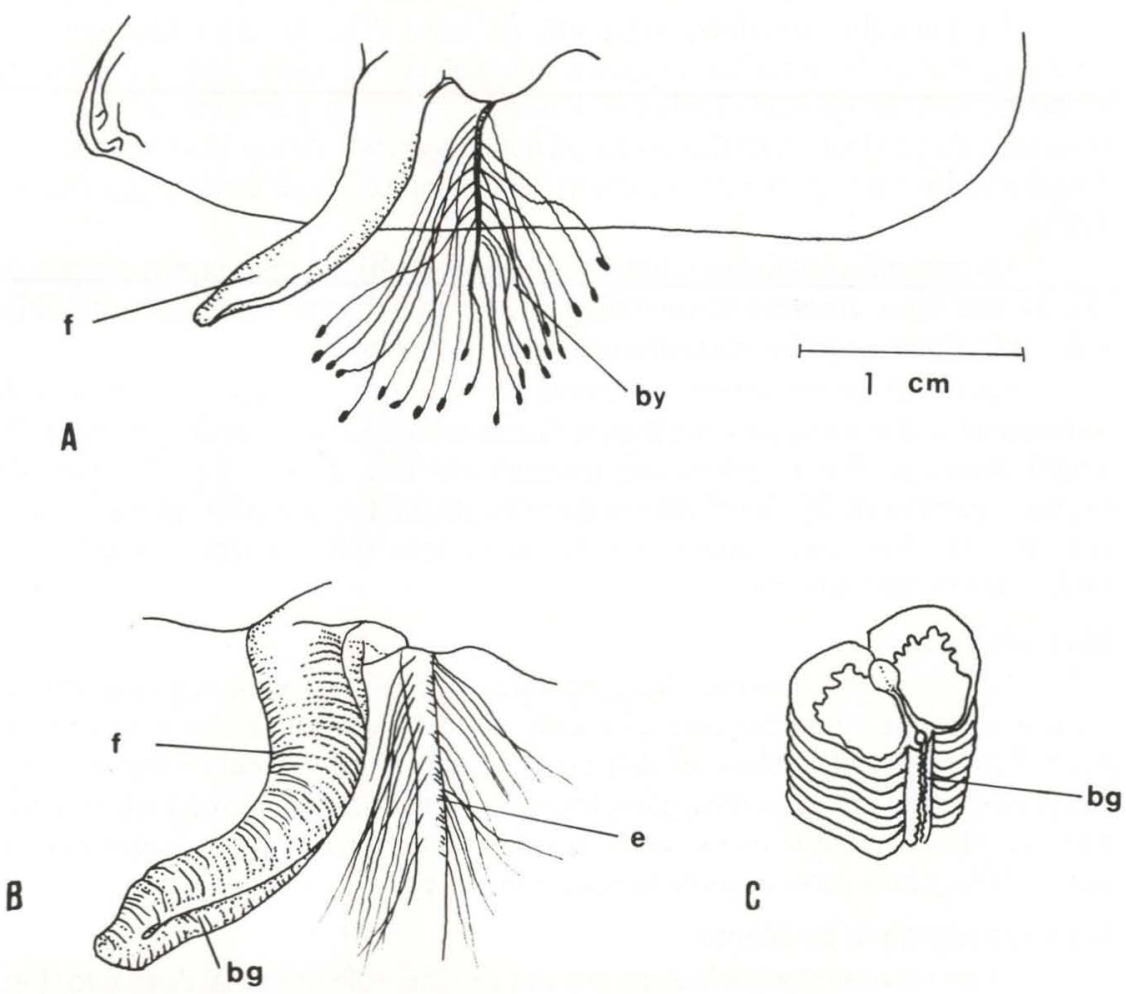

\section{7}

Fig. 7. Perna perna, pé e bisso. (A) aspecto geral; (B) aspecto lateroventral; (C) corte transversal do pé, (bg) sulco do bisso, (by) bisso, (e) eixo principal do bisso, (f) pé.

O pé tem inserção anterior no corpo do animal, sendo musculoso e, em média, varia de menos de $1 \mathrm{~cm}$ até quase $3 \mathrm{~cm}$ de comprimento dependendo do estado de contração; em animais de $4 \mathrm{~cm}$ de comprimento, apresentou uma intensa pigmentação marrom.

Não há evidência de nenhuma corrente ciliar na superfície do pé em $P$. perna. KELLOGG (1915) estudou os mecanismos ciliares em 34 espécies de várias famílias de bivalves. Aquele autor acreditava que a superfície do pé em todos os bivalves adultos tivesse perdido sua ciliação embrionária. Para ele, o pé não é ciliado em 
nenhum bivalve adulto. Porém, vários autores, entre eles, NARCHI (1974b) em Petricola typica (Jonas, 1844) e AVELAR \& NARCHI (1984) em Brachidontes darwinianus darwinianus, evidenciaram ciliação no pé de animais adultos. WHITE (1937), ao descrever o pé de Mytilus edulis, observou ser ele coberto por um epitélio ciliado.

O bisso é constituído por um eixo principal de cerca de $1 \mathrm{~mm}$ de espessura, de comprimento variável, do qual parte um grande número de filamentos secundários. Na região do eixo principal, próximo à glândula bissogênica, esses filamentos secundários são nitidamente distribuídos em duas fileiras longitudinais, de situação diametralmente opostas. Na região distal do eixo, essa distribuição é mascarada pelo emaranhado dos filamentos.

Cada filamento tem, em sua extremidade distal, um disco de fixação, com o qual o animal se fixa ao substrato rochoso.

A formação dos filamentos do bisso foi observada em animais colocados em aquários, olhando-se através da parede de vidro onde eles se fixavam. Inicialmente o animal toca várias vezes o vidro, em um comportamento exploratório e, a seguir, aplica a face ventral do pé sobre ele. A glândula bissogênica elimina, então, muito lentamente, uma substância líquida pastosa de cor amarelada, que é pressionada para o sulco ventral através de movimentos musculares do pé e do corpo do animal. Essa substância preenche o sulco, agora fechado em canal e chega até a cavidade terminal do sulco, onde é forçada contra o substrato. Nessa região forma-se o disco adesivo terminal. O pé é, então, retirado lentamente, liberando o filamento contido no sulco que mostra ser contínuo com o eixo principal do bisso. WhITE (1937) relata a descrição da formação do bisso em Mytilus edulis feita por WILLIAMSON (1907 apud WHITE 1937), que é muito semelhante à descrição aqui registrada, acrescentando que os filamentos endurecem ao contato com a água do mar, e que o disco de fixação de sua extremidade é produzido por uma secreção adesiva das glândulas purpúreas, que se localizam no sulco do pé próximas a sua fosseta terminal. O filamento, assim que se torna visível, é amarelado, enquanto WHITE (1937) observou que inicialmente tinham coloração branca.

Os filamentos são produzidos, portanto, por modelagem neste sulco pedioso e não pela secreção em forma filamentosa. O bisso é secretado em forma de lamelas (BOUTAN 1895). Em Mytilus edulis os filamentos bissais são formados por proteínas "fenólicas" originárias das glândulas purpúreas, formação essa que ocorre no sulco, sob a ação de polifenovidases (PUJOL 1967).

\section{Cavidade do Manto}

\section{Topografia}

A disposição dos principais órgãos da cavidade do manto está detalhada nas figuras 8 e 9, não havendo necessidade de descrição pormenorizada.

As considerações principais, válidas para a espécie em estudo, são as seguintes :

a) A massa visceral e o manto, nos animais sexualmente maduros, apresentam coloração amarelada nos machos e avermelhada nas fêmeas. 

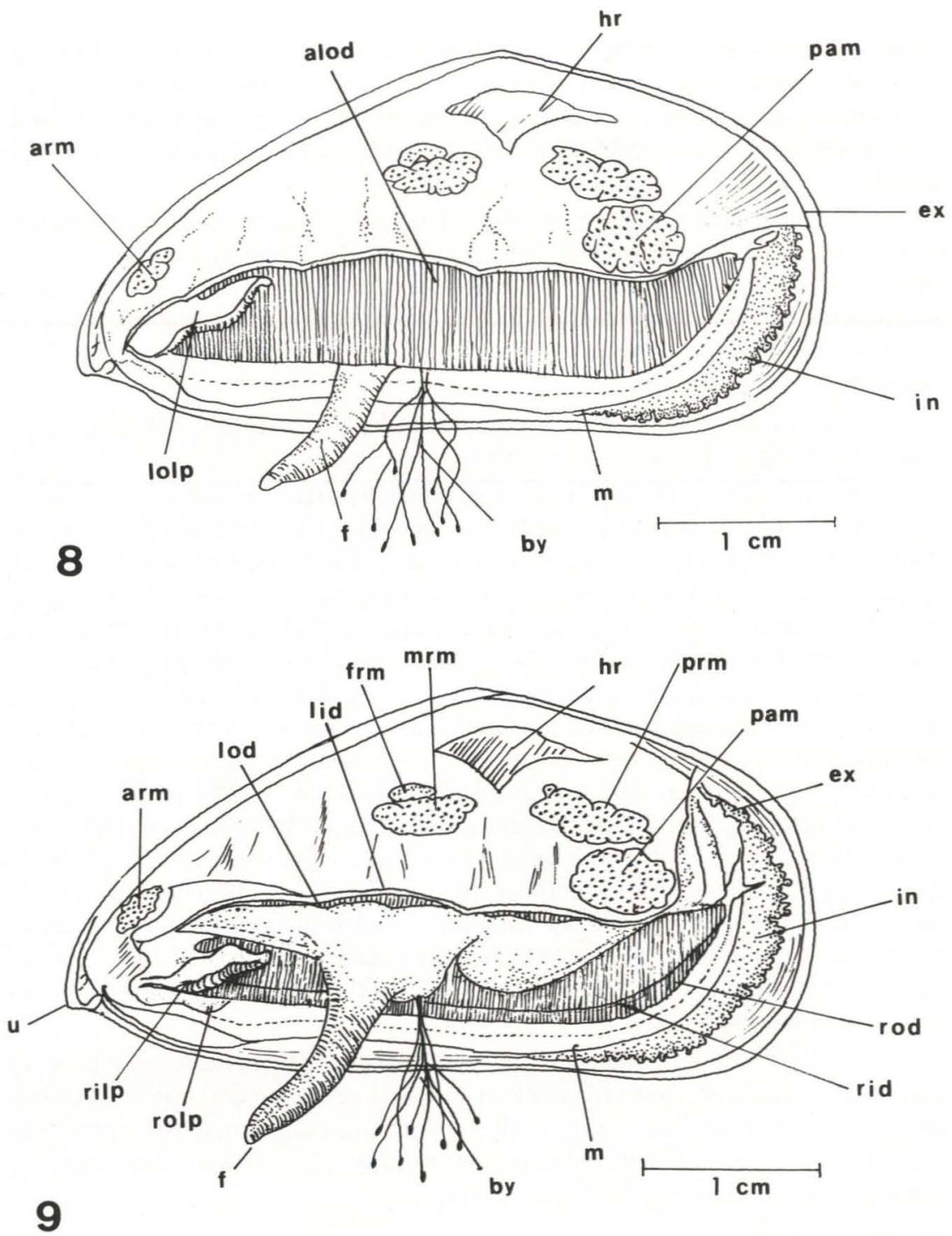

Figs 8-9. Perna perna, topografia da cavidade palial, vista do lado esquerdo do animal. (8) Após a remoção de parte do manto; (9) após a remoção de parte do manto e do ctenídio esquerdo. (alod) lamela ascendente da demibrânquia externa, (arm) músculo anterior retrator do bisso, (by) bisso, (ex) sifão exalante, (f) pé, (frm) músculo retrator do pé, (hr) região do coração, (in) sifão inalante, (lid) resto demibrânquia interna esquerda, (lod) resto da demibrânquia externa esquerda, (lolp) palpo esquerdo externo, (m) manto, (mrm) músculo mediano retrator do bisso, (pam) músculo adutor posterior, (prm) músculo posterior retrator do bisso, (rid) demibrânquia interna direita, (rilp) palpo labial interno direito, (rod) demibrânquia externa direita, (rolp) palpo labial externo direito, (u) umbo. 
b) Os ctenídios estendem-se para a região posterior até a base do processo sifonal. Não existe extenção supra-axial.

c) As demibrânquias externa e interna são aproximadamente de igual comprimento e altura, sendo a externa pouco mais alta.

d) As bordas ventrais do manto não se fundem, continuando-se pelo sifão inalante. A cavidade palial é separada da abertura do sifão inalante por uma membrana sifonal.

e) Os palpos labiais são bem desenvolvidos. Em P. perna chegam até cerca de um quarto do comprimento do animal.

\section{Ctenídios}

Os ctenídios pertencem ao tipo B(1) da classificação de ATKINS (1936c), com a demibrânquia interna semelhante à externa, apresentando aproximadamente o mesmo tamanho (Fig. 10). Esse é o tipo característico de Mytilidae e Pinnidae. Não há extensão supra-axial. As brânquias são filibranquiadas, planas e homorrábdicas (todos os filamentos são iguais entre si). Em $P$. perna os filamentos são ligados entre si por discos ciliares existentes em grande número (de 15 a 20), que partem de pequenas elevações laterais. A porção descendente de cada filamento liga-se à porção ascendente do mesmo filamento por junções interlamelares, em forma de barras, de três a quatro por filamento. Essa junção interlamelar é característica dos Mytilacea (WHITE 1937). A borda superior das lamelas ascendentes de ambas as demibrânquias apresentam projeções laterais que as ligam entre si, mas são livres da massa visceral e do manto, como em Mytilus, edulis e Mytilus magellanicus (Chemntz, 1785), como observou RIDEWOOD (1903).

Cada filamento apresenta uma faixa frontal longitudinal de cílios frontais, com cerca de $8 \mu \mathrm{m}$ de comprimento (Figs 11-12, fc), ladeada por duas faixas de grandes cílios eu-látero-frontais (lfc), tendo cada um cerca de $15 \mu \mathrm{m}$ de comprimento em $P$. perna. Os cílios laterais (lc), medem cerca de $15 \mu \mathrm{m}$ de comprimento cada um e aparecem formando duas fileiras largas situadas nas faces laterais dos filamentos.

Não conseguimos evidenciar a presença de cílios pro-látero-frontais. Esses cílios dispõem-se em duas fileiras, cada uma ladeando os cílios eu-látero-frontais, sendo porém facilmente mascaradas por eles (ATKINS 1936c). Os cílios pro-láterofrontais são encontrados em bivalves com cílios eu-látero-frontais, incluindo Mytilus edulis (ATKINS 1936c), embora WHITE (1937) não se refira a eles em seu estudo sobre essa espécie. Também não foram evidenciados por AVELAR \& NARCHI (1984) em Brachidontes darwinianus darwinianus. Segundo ATKINS (1936c) esses cílios talvez ocorram sempre nesses bivalves, embora nem sempre sejam reconhecidos devido às dificuldades de observação ou imperfeita preservação do material. Estudos recentes de MOORE (1971) e OWEN (1974), usando microscopia eletrônica de varredura, confirmaram a presença de cílios pro-látero-frontais em Mytilus edulis.

Os cílios eu-látero-frontais ocorrem em espécies de todas as ordens de Bivalvia, sendo apontados, em Filibranchiata, apenas nas famílias Trigoniidae e Mytilidae. Nessa última família já haviam sido observados anteriormente em Mytilus edulis, Modiolus modiolus (Linné, 1758), Modiolus adriaticus, Musculus 
(=Modiolaria) marmoratus (Forbes, 1838), Musculus (=Crenela) discors (Linné, 1767) por ATKINS (1936c) e em Brachidontes darwinianus darwinianus por AvELAR \& NARCHI (1984).

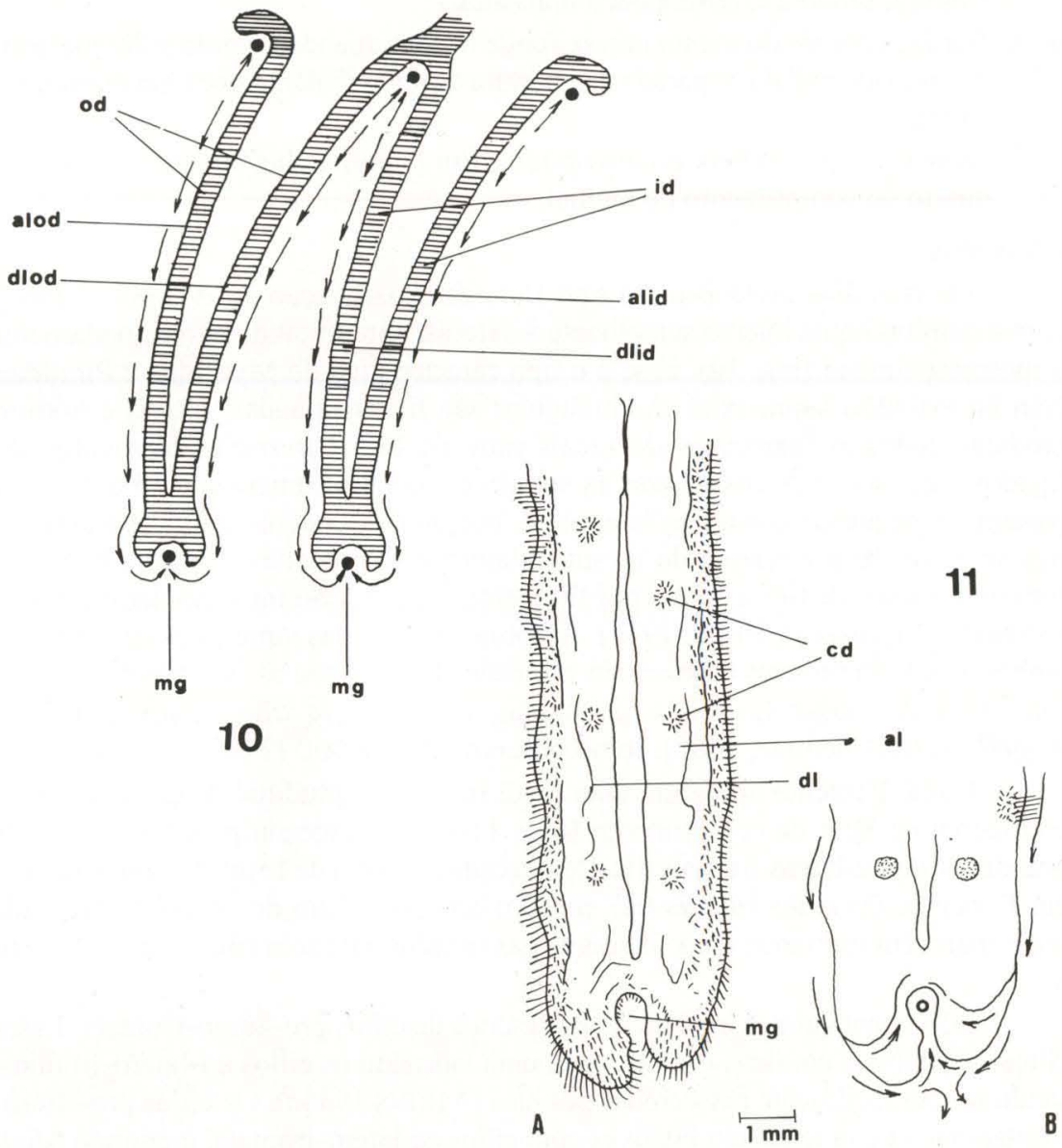

Figs 10-11. Perna perna. (10) Esquema da secção transversal do ctenídio, mostrando a direção das correntes frontais; (11A) porção terminal de um filamento branquial; (11B) correntes frontais nessa porção. (al) Lamela ascendente, (alid) lamela ascendente da demibrânquia interna, (alod) lamela ascendente da demibrânquia externa, (cd) discos ciliares, (dl) porção descendente do filamento, (dlid) lamela descendente da demibrânquia interna, (dlod) lamela descendente da demibrânquia externa, (id) demibrânquia interna, (mg) sulco marginal, (od) demibrânquia externa, $(\bullet)$ correntes com direção oral.

$\mathrm{Na}$ borda ventral de cada demibrânquia existe um sulco marginal ciliado ( $\mathrm{mg}$ ), bastante profundo em ambas as espécies. Outro sulco profundo forma-se na região dorsal, na junção da lamela descendente da demibrânquia interna com a lamela descendente da demibrânquia externa. Dois sulcos rasos são delimitados por 
leves dobramentos na borda dorsal de cada filamento, tanto da lamela ascendente da demibrânquia interna (próximo ao epitélio da massa visceral), quanto da lamela ascendente da demibrânquia externa (próximo ao manto). Em todos esses cinco sulcos existem correntes ciliares em direção oral.

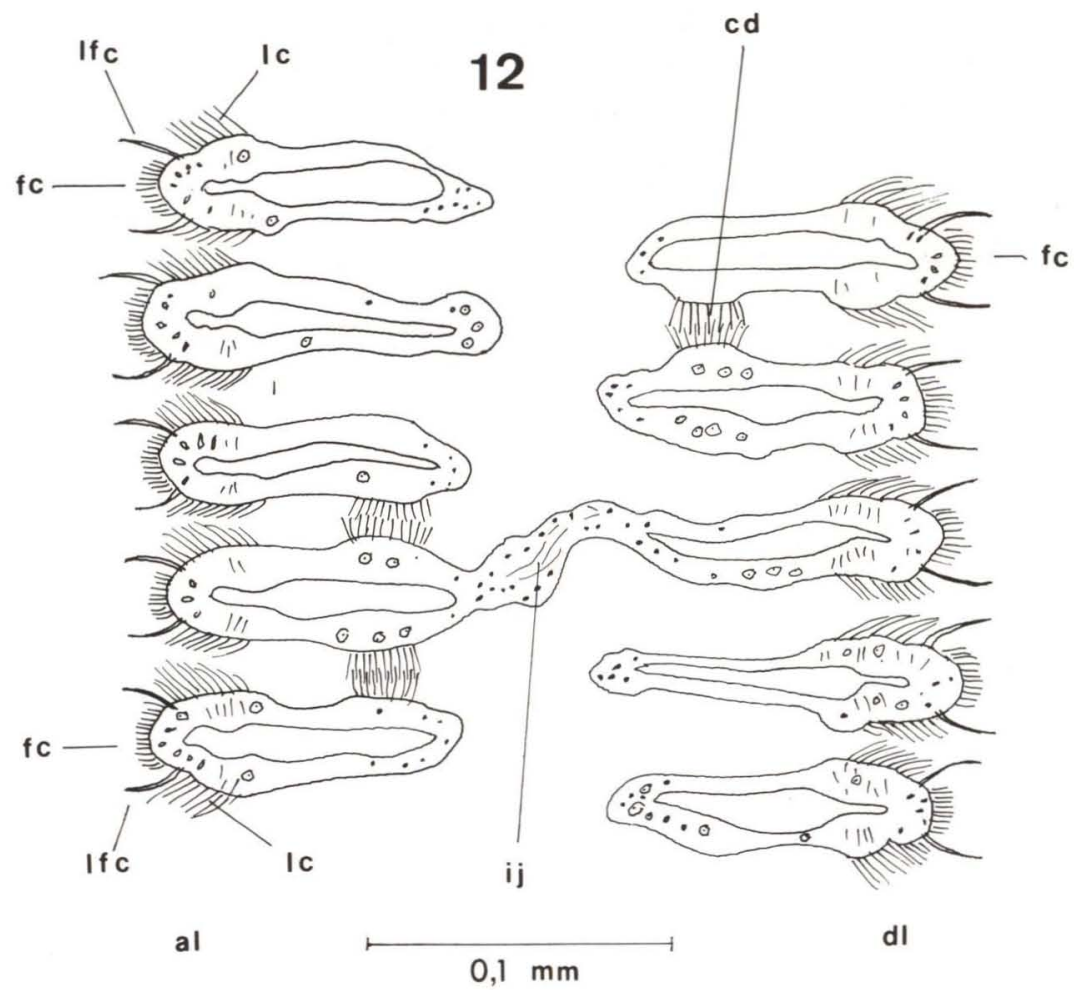

Fig. 12. Perna perna. Corte transversal de uma demibrânquia. (al) Lamela ascendente, (cd) discos ciliares, (dI) lamela descendente, (fc) cílios frontais, (ij) junção interlamelar, (Ic) cílios laterais, (Ifc) cilios eu-látero-frontais.

O padrão de correntes nas superfícies dos ctenídios é o mesmo encontrado por NARCHI \& GALVÃo-BUENO (1983) em Mytella charruana. Em ambas as demibrânquias as correntes ciliares são dirigidas para a região ventral, carregando as partículas para o sulco ciliar marginal. Apenas numa pequena faixa longitudinal que margeia a porção dorsal dos ctenídios as correntes são dirigidas para a região dorsal, conduzindo partículas para as bordas das lamelas ascendentes e para a origem das lamelas descendentes. As partículas transportadas passam, nessas regiões, para correntes de aceitação, com direção oral.

Os cílios frontais batem continuamente levando partículas para a região ventral. Os cílios eu-látero-frontais, maiores que os frontais, são mais ou menos rígidos e guardam a passagem interfilamentar; por essa razão MOORE (1971) e 
OWEN (1974) preferem usar o termo cirro ao invés de cílio. Seu batimento, levando partículas para os cílios frontais não é contínuo, aumentando porém quando partículas de maior diâmetro são adicionadas. Na porção ventral, as fileiras dos cílios eu-látero-frontais curvam-se antes do término dos filamentos, em direção à base do sulco longitudinal ventral do ctenídio. Além desse nível, os cílios ventrais espalham-se, coletando e conduzindo partículas para o sulco marginal.

Esse sulco marginal, que ocorre em Mytella charruana e P. perna, foi evidenciado também em Brachidontes darwinianus darwinianus por AVELAR \& NARCHI (1984) e em vários gêneros diferentes como Solenocurtus Brainville, 1824, Lutraria Lamarck, 1799, Cardium Linné, 1758, Zirphaea Gray, 1842 e Barnea Risso, 1826 por ATKINS (1936b), Anomalocardia e Tivela por NARCHI (1972), Adula Adams, 1857 (FANKBONER 1971), Iphigenia Schumacher, 1817 e Donax Linné, 1758 por NARCHI (1974a) e em muitos outros, ora nas duas demibrânquias, ora apenas na interna. Este sulco marginal é associado por ATKINS (1936c) e por KELLOGG (1915) a mecanismos de triagem, principalmente por limitar o tamanho das partículas que nele caem e são levadas à boca.

Cílios de guarda, que tornam esse mecanismo mais eficiente, não foram observados nem em Mytella charruana e nem em $P$. perna, como também não ocorrem em Brachidontes darwinianus darwinianus (AVELAR \& NARCHI 1984), em Mytilus edulis e Modiolus modiolus, embora apareçam em outras espécies de Mytilidae : Modiolus adriaticus (Lamarck, 1819), Modiolus phaseolinus Philippi, 1844, Musculus discors, Musculus marmoratus (ATKINs 1936b) e em Adula (Botula) falcata (Gould, 1851) (FANKBONER 1971).

\section{Palpos Labiais}

Os palpos têm aproximadamente um quarto do comprimento do animal e são simétricos dois a dois (Fig. 13). Os palpos externos localizam-se entre o manto e a demibrânquia externa; os palpos internos situam-se entre a massa visceral e a demibrânquia interna. Como em Mytilus edulis (RIDEWOOD 1903; WHITE 1937), Adula (Botula) falcata (FANKBONER 1971), Brachidontes darwinianus darwinianus (AVElAR \& NARCHI 1984) e Mytella charruana (NARCHI \& GALVÃo-BUENO 1983) e Perna viridis (MORTON 1987), as faces voltadas para as brânquias são intensamente pregueadas na espécie $P$. perna aqui estudada, enquanto que as faces opostas a elas são lisas.

A face do palpo voltada para a brânquia apresenta duas zonas separadas por uma dobra longitudinal que se estende por todo o comprimento do mesmo. Essa dobra é muito saliente, tendo quase a metade da largura do palpo. Quando em secção transversal, este apresenta o aspecto de um "Y" invertido (Fig. 14).

A região ventral, delimitada por essa dobra longitudinal, apresenta muitas pregas transversais que se estendem ventralmente e ultrapassam a margem ventral, terminando num pequeno sulco na face lisa do palpo. Essa zona pregueada é coberta parcialmente pela dobra longitudinal.

A zona localizada dorsalmente à dobra, bem como toda a face oposta a ela, é lisa, sem pregas, mas com cílios.

As dificuldades do estudo das correntes ciliares nos palpos labiais foram 
apontadas por KELLOGG (1915), NARCHI (1972) e MORTON (1987), e podem levar a erros de omissão.

NARCHI \& GALVÃo-BUENo (1983) observaram que os palpos de Mytella charruana são bastante longos, atingindo até a metade do corpo do animal, o que não acontece porém em $P$. perna, cujos palpos não excedem a um quarto do comprimento do animal.
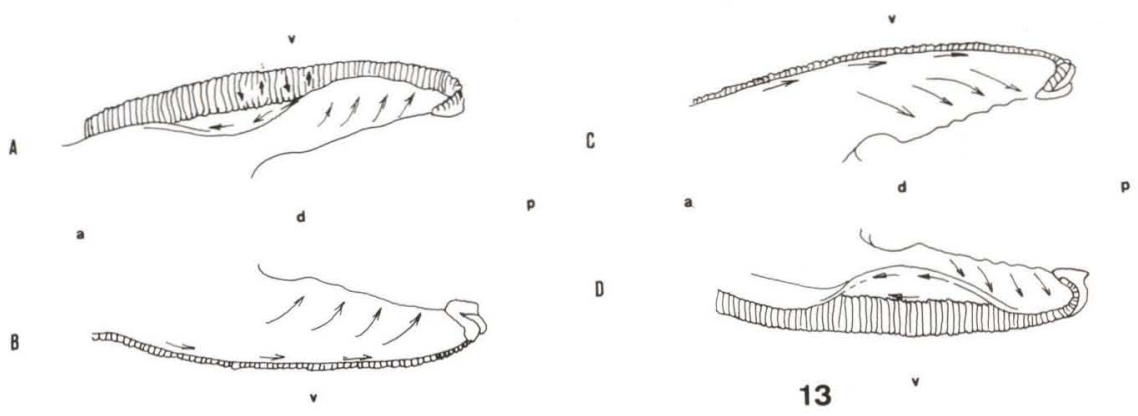

Fig. 13. Perna perna, aspecto funcional dos palpos. (A-B) Vista interna e externa do palpo externo esquerdo; (C-D) vista externa e interna do palpo interno esquerdo. As setas indicam o caminho das partículas. (a) Região anterior, (d) região dorsal, (p) região posterior, (v) região ventral.

O estudo dos palpos é difícil. A fragilidade dos mesmos é um obstáculo à sua manipulação. Nas condições normais, as dobras apresentam-se encostadas umas às outras, impedindo a análise da região profunda entre elas, o que só é possível com o dobramento do palpo.

As correntes ciliares observadas nos palpos foram representadas, de forma esquemática, nas figuras 13-15, e são as seguintes:

Correntes transversais:

1.1 - correntes em direção dorsal, na face lisa não voltada para as brânquias;

1.2 - correntes em direção ventral, na zona dorsal (não pregueada) da face voltada para as brânquias;

1.3 - correntes em direção à margem livre, na zona ventral da dobra longitudinal do palpo;

1.4 - correntes em direção ventral, nas cristas das pregas transversais;

1.5 - correntes em direção dorsal, entre as pregas transversais.

Correntes longitudinais de aceitação (ápice - base do palpo):

2.1 - correntes na face interna da margem livre ventral da dobra longitudinal;

2.2 - corrente na intersecção da dobra longitudinal com a face pregueada. Correntes longitudinais de rejeição (base - ápice do palpo):

3.1 - corrente no sulco ventral, onde terminam as pregas transversais. 

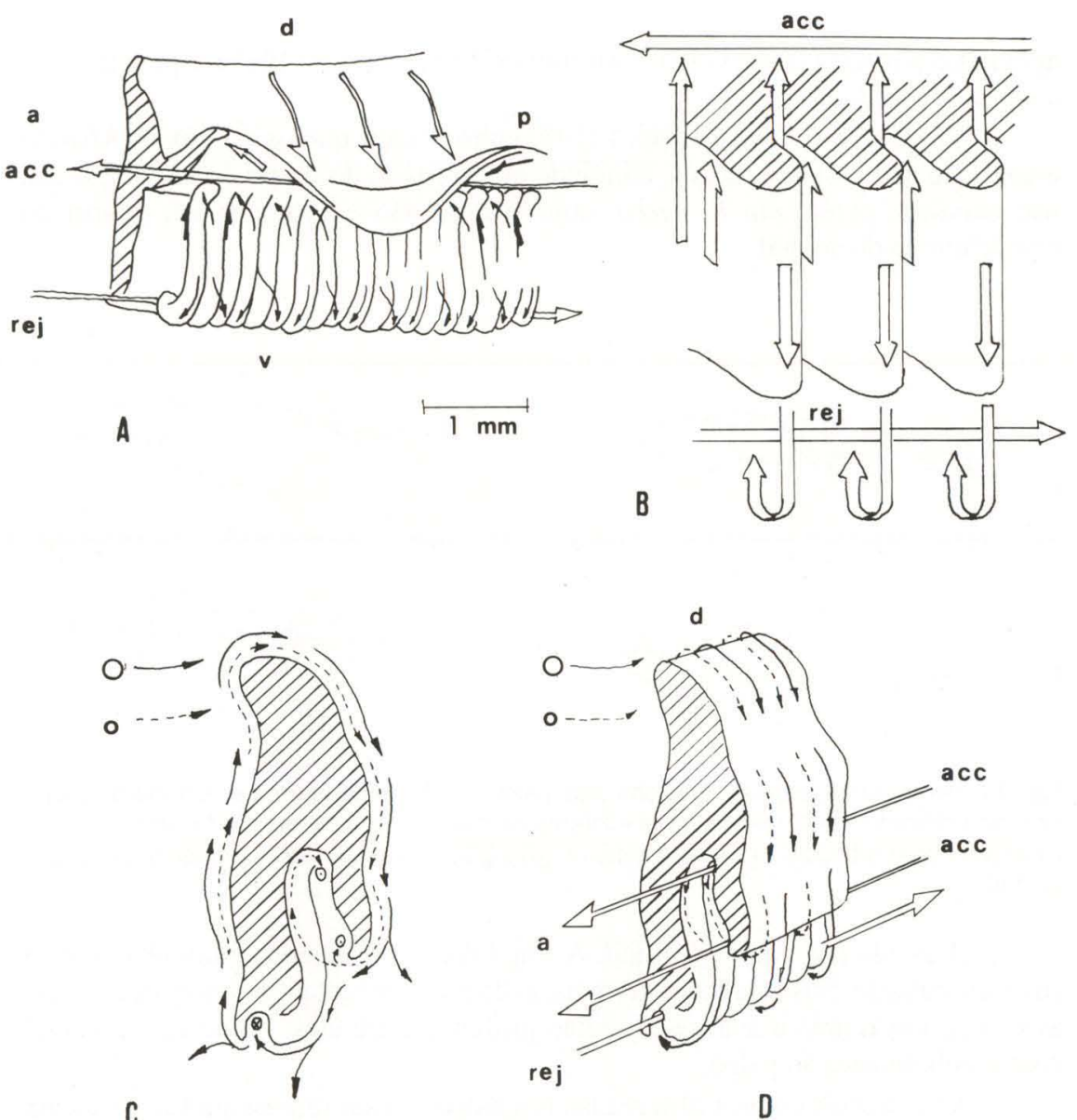

\section{4}

Fig. 14. Perna perna, representação semiesquemática das correntes ciliares na superfície dos palpos. (A) Correntes ciliares na face pregueada; (B) pequena seção das pregas; (C-D) mecanismo de triagem. As setas indicam o caminho das partículas. (a) Região anterior, (acc) correntes de aceitação, (d) região dorsal, (p) região posterior, (rej) correntes de rejeição, (v) região ventral. (em C-D: $\rightarrow$ partículas grandes; $\cdots . . \rightarrow$ partículas pequenas).

Todas as correntes transversais, com exceção das correntes em direção dorsal entre as pregas (1.5), circundam o palpo sempre no mesmo sentido, passando dorsalmente pela face externa não pregueada, daí para a face interna voltada para as brânquias e, então, ventralmente sobre esta (Figs 14-15).

As partículas que chegam até o palpo são triadas de acordo com o seu tamanho (Fig. 14). As que incidem na face lisa externa do palpo são carregadas, pela borda dorsal, à face oposta, de onde são levadas pelos batimentos ciliares até a borda livre da dobra longitudinal. Como esta recobre parcialmente a região 

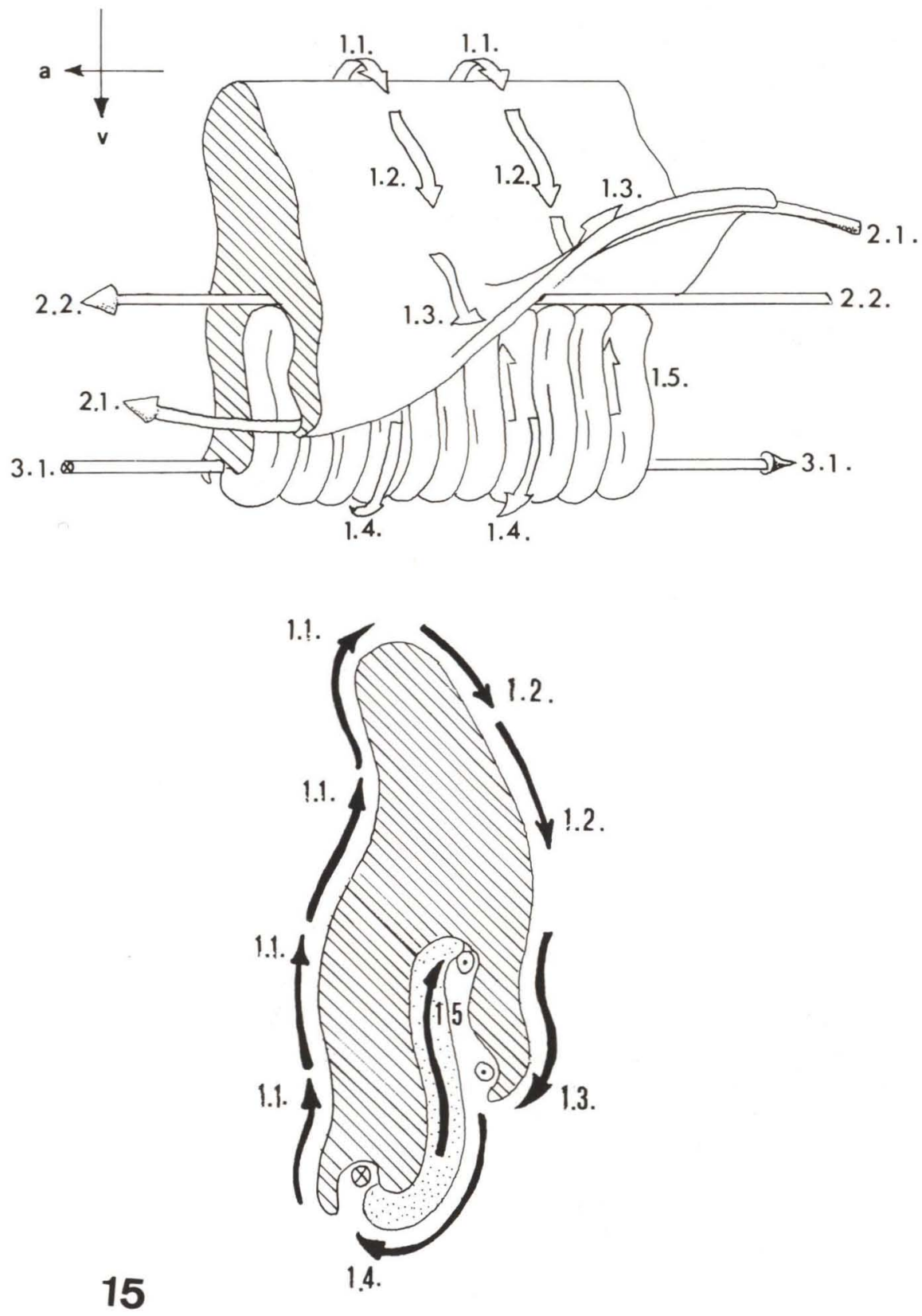

Fig. 15. Perna perna, representação esquemática das correntes ciliares nos palpos labiais. As correntes são indicadas pelos números citados no texto. (a) Região anterior, (v) região ventral. 
pregueada, as partículas são dirigidas para as pregas transversais. As partículas pequenas passam para os sulcos entre as pregas e são carregadas para a intersecção da dobra longitudinal com a zona pregueada, onde são capturadas pela corrente de aceitação e daí vão para a boca do animal. As partículas maiores, que não penetram nesses sulcos, são carregadas pelos cílios das cristas das pregas até o ápice destas, na borda ventral do palpo, onde são captadas pela corrente longitudinal de rejeição, ou são novamente enviadas à face lisa do palpo, ou caem finalmente na superfície do manto, de onde são eliminadas pelas correntes de rejeição deste (Fig. 16).

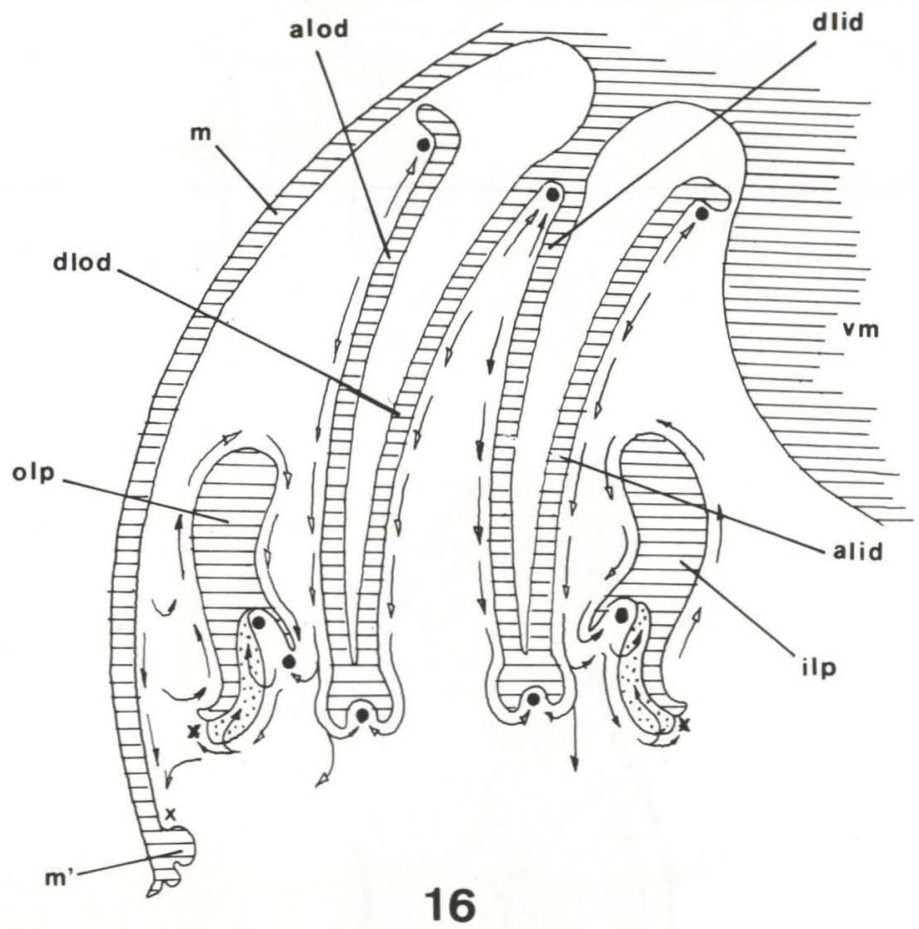

Fig. 16. Perna perna, representação esquemática dos mecanismos ciliares da cavidade palial. (alid) Lamela ascendente da demibrânquia interna, (alod) lamela ascendente da demibrânquia externa, (dlid) lamela descendente da demibrânquia interna, (dlod) lamela descendente da demibrânquia externa, (ilp) palpo labial interno, (m) manto, ( $m$ ') borda do manto, (olp) palpo labial externo, $(\mathrm{vm})$ massa visceral, $(\bullet)$ correntes de aceitação, $(\mathrm{x})$ correntes de rejeição.

A atividade muscular das pregas de $P$. perna, separando-as ou aproximando-as, já foram evidenciadas por KELLOGG (1915), ANSELL (1961), NARCHI (1974a), HEBLING (1976), AVELAR \& NARCHI (1984) e NARCHI \& GALVÃO-BUENO (1983) em outros bivalves. Teve-se a oportunidade de observar também a atividade muscular do próprio palpo. O animal tem a capacidade de enrolar o palpo em espiral sobre a face pregueada, formando praticamente um tubo. Na luz desse tubo e em suas paredes forma-se então uma forte corrente de rejeição. Essa configuração do 
palpo ocorre quando ele é bastante irritado pelo contato com o pincel, estilete, ou com a inclusão de partículas grandes de carmim. Esta reação já descrita para Mytella charruana (NARCHI \& GALVÃO-BUENO 1983), já havia sido anteriormente observada por KELLOGG (1915) em Schizoterus nuttallii Conrad, 1853.

\section{Região Bucal}

A região bucal de $P$. perna (Fig. 17) é praticamente idêntica a de Mytella charruana (NARCHI \& GALVÃO-BUENO 1983). A boca fica protegida pela aposição de uma dobra que une os palpos externos sobre ela, como em Mytilus edulis, Mytilus californianus (Kellogg 1915) e Perna viridis (MORTON 1987). Pelo afastamento dessa dobra pode-se estudar as correntes ciliares da região bucal.

As partículas que chegam pelos sulcos marginais das brânquias e pelas correntes de aceitação dos palpos caminham juntas para a porção bem anterior da boca, por baixo da dobra que a recobre, na goteira oral proximal (pog). Na extremidade anterior de cada palpo, porém, ocorre uma reversão nas margens dessa corrente, rejeitando partículas. Essas são lançadas na corrente de rejeição dos palpos ou sobre a borda do manto.

\section{Superfície do Manto}

Para o estudo da ciliação da superfície do manto foram removidos a massa visceral e ctenídios. Após o relaxamento muscular, as correntes foram observadas pela adição do carmim, aquadag e carborundum.

Em $P$. perna duas regiões de atividade ciliar foram evidenciadas na superfície do manto, com sentido ventral e posterior (Fig. 18). A primeira reduz-se a uma pequena área na região anterior, que se estende do ápice da concha até aproximadamente a região bucal. Essa zona recebe as rejeições da área bucal. A segunda região ocupa desde o primeiro terço do animal até a região do sifão inalante. A superfície entre essas duas áreas não apresenta correntes ciliares. A velocidade das correntes também não é uniforme, sendo maior nos extremos e na parte ventral. Em Mytella charruana (NARCHI \& GALVÃO-BUENO 1983) onde o palpo labial é grande, essa área posterior estende-se desde a região mediana até o sulco de rejeição dorsal do sifão inalante.

No lado ventral, paralela à borda do manto, existe em P. perna uma forte corrente de rejeição que se estende desde o ápice da concha até o sifão inalante.

\section{Canal Alimentar}

\section{Estrutura Geral}

A disposição geral do canal alimentar de $P$. perna é muito semelhante àquela descrita por NARCHI \& GALVÃO-BUENO (1983) para Mytella charruana.

O esôfago (Fig. 19, oe) é achatado dorso-ventralmente, abrindo-se na parte ântero-ventral do estômago globular. Este localiza-se na região mediana da massa visceral e é mais anterior em $P$. perna do que em Mytella charruana.

Em P. perna o intestino (mg) e o saco do estilete (ss) constituem um único tubo, internamente dividido. O saco do estilete e o intestino continuam-se para a parte posterior da massa visceral, e na altura do músculo adutor posterior o saco do estilete termina. $\mathrm{O}$ intestino curva-se, então, para o lado direito do animal, dirige-se 
para a região anterior, onde sobre o estômago, curva-se para o lado esquerdo. Continua-se, a seguir, em direção ao pericárdio (pe) onde, em seu interior, atravessa $\mathrm{o}$ ventrículo. Após abandonar o pericárdio, o intestino passa novamente sobre $\mathrm{o}$ músculo adutor posterior (pam) e vai se abrir no ânus (ap).

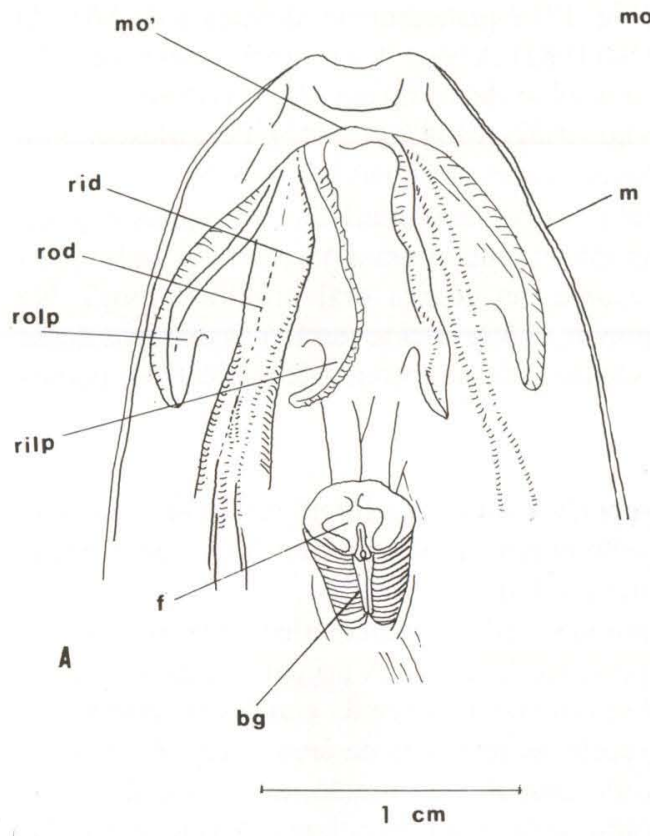

17
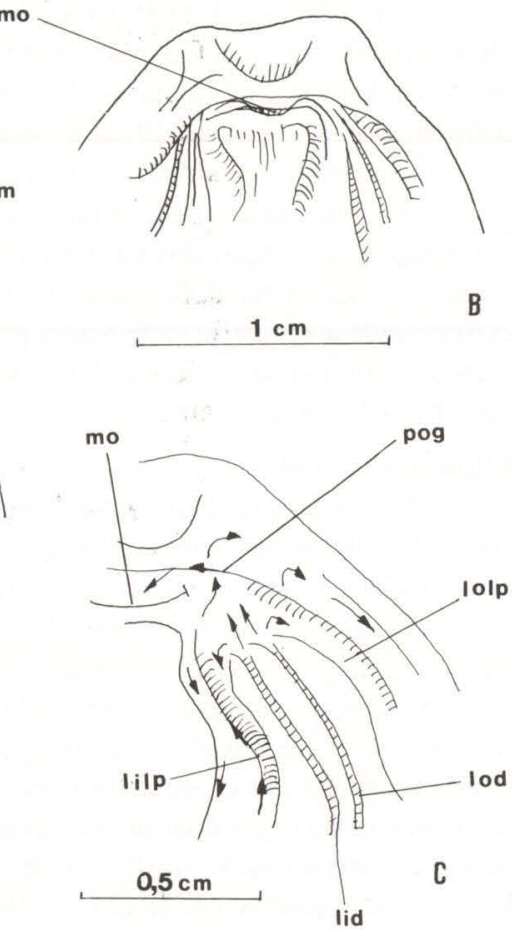

Fig. 17. Perna perna, região bucal, em vista ventral. (A) Topografia geral onde o pé aparece secionado; (B) boca, exposta pelo afastamento dos palpos externos; (C) correntes ciliares na região bucal. (bg) Sulco do bisso, (f) pé secionado, (lilp) palpo labial esquerdo interno, (lolp) palpo labial esquerdo externo, (lid) demibrânquia esquerda interna, (lod) demibrânquia esquerda externa, ( $\mathbf{m}$ ) manto secionado, ( $\mathrm{mo}$ ) boca, (mo') região da boca, (pog) goteira oral proximal, (rid) demibrânquia direita interna, (rod) demibrânquia direita externa, (rilp) palpo direito interno, (rolp) palpo labial direito externo.

\section{Estrutura Detalhada do Estômago}

O estômago de $P$. perna (Fig. 20) pertence ao tipo III da classificação de PURCHON (1957) apresentando, porém, algumas variações : o capuz dorsal (Fig. 19, dh) é grande. O estômago de P. perna é mais semelhante ao de Mytilus edulis (GRAHAM 1949) do que ao de Pinctata Röding, 1798 descrito por PURCHON (1957). Como em Malleus Lamarck, 1799 (PURCHON 1957), não existe área de triagem de dobras e sulcos na porção anterior da língua da tiflosole maior; esta tem a mesma tendência que nas espécies citadas, de aprofundar-se na região ventral anterior da 
parede do estômago, formando uma espiral fechada, que é mais complexa do que a de Pinctata e Malleus. A tiflosole maior (Fig. 20, ty) desaparece no ceco (c), denominado de divertículo ventral por WHITE (1937).
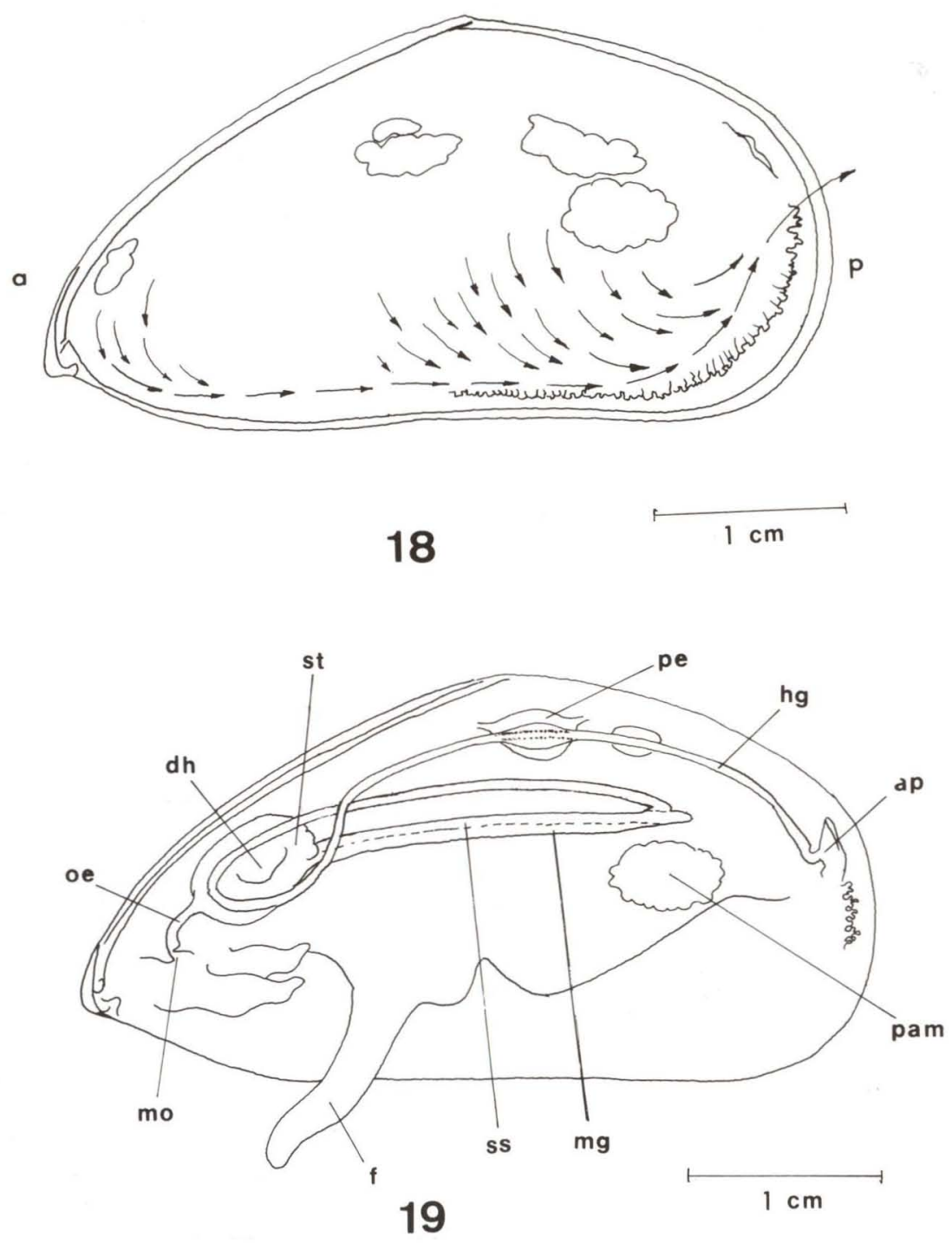

Figs 18-19. Perna perna. (18) Correntes ciliares na superfície do manto; (19) representação semiesquemática do aparelho digestivo, visto do lado esquerdo do animal. (a) Região anterior, (ap) papila anal, (dh) capuz dorsal, (f) pé, (hg) intestino posterior, ( $\mathrm{mg}$ ) intestino médio, (mo) boca, (oe) esôfago, (p) região posterior, (pam) músculo adutor posterior, (pe) pericárdio, (ss) saco do estilete, (st) estômago. 


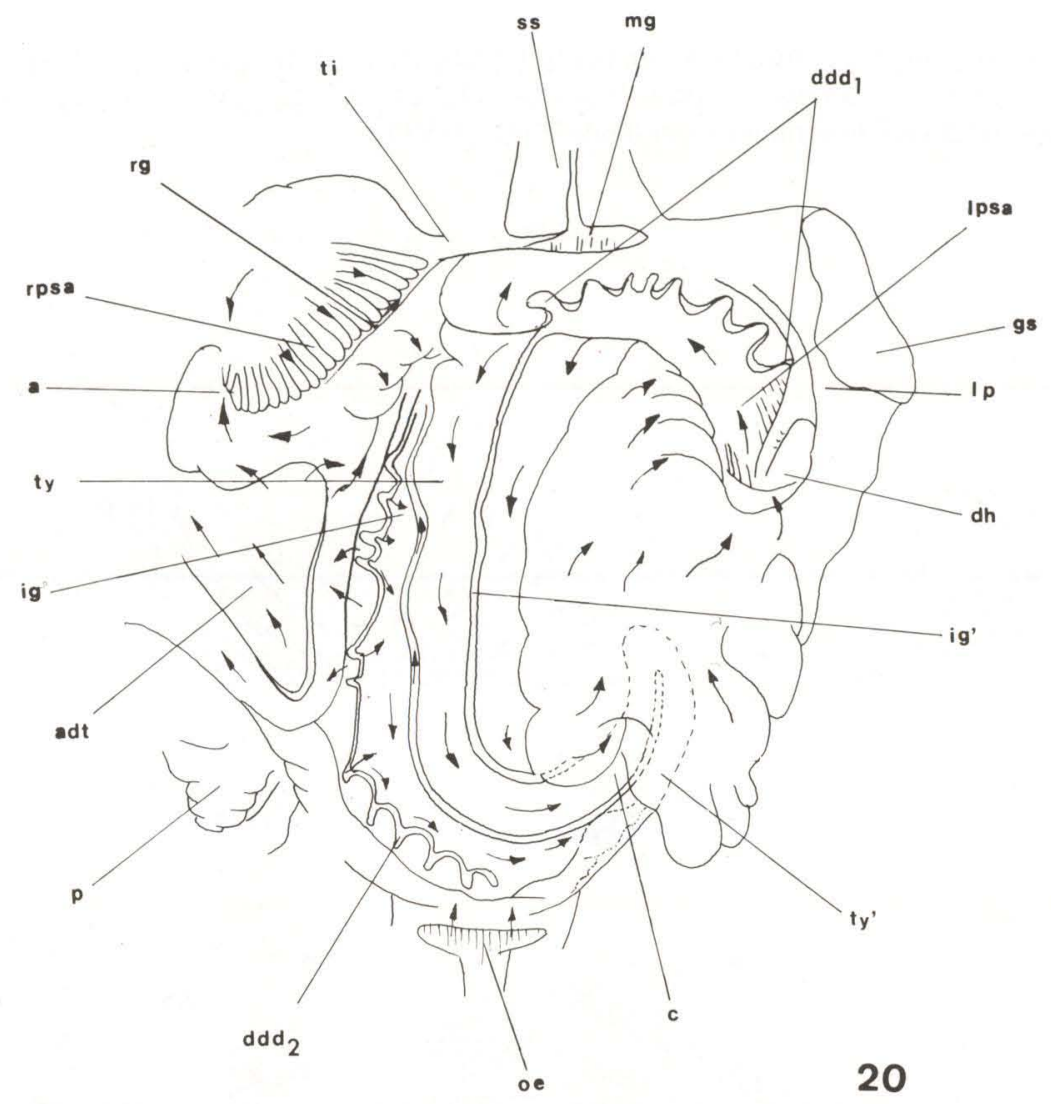

Fig. 20. Perna perna, representeação esquemática da estrutura e correntes ciliares principais do estômago, aberto, em vista dorsal. Correntes ciliares indicadas por setas. (a) Apêndice, (adt) trato ântero-dorsal, (c) ceco digestivo, $\left(\mathbf{d d d d}_{1}\right.$ ) orifícios dos dutos do divertículo digestivo no interior da bolsa esquerda, $\left(\mathbf{d d d}_{2}\right)$ orifícios dos dutos do divertículo digestivo na parede ântero-ventral, (dh) capuz dorsal, (gs) escudo gástrico, (ig) sulco intestinal, (ig') início do sulco intestinal, (Ipsa) área de triagem posterior esquerda, ( $\mathrm{mg}$ ) abertura do intestino médio, (oe) esôfago, (p) projeção do assoalho do estômago, (rg) sulco de rejeição, (rpsa) área de triagem posterior direita, (ss) saco do estilete, (ti) tiflosole menor, (ty) tiflosole maior, (ty') língua da tiflosole maior.

A tiflosole maior (ty) localiza-se no assoalho do estômago e forma, na região anterior, uma língua (ty') em espiral fechada para o lado esquerdo. Em seguida entra no ceco de triagem de partículas (c), o qual, nesse caso, permanece no lado ventral do estômago, como em Ostrea parasitica Gmelin, 1878 (PURCHON 1957). A língua da tiflosole maior (ty') de $P$. perna dobra-se dentro do ceco e volta novamente à luz do estômago, como em Perna viridis Linné, 1758, Modiolus undulata (Lamarck, 1819), Modiolus striatus (Barnes, 1823) e Arcuatula Lamy, 1919 (DINAMANI 1967).

A tiflosole menor (ti) termina na parede posterior direita do estômago, anterior ao orifício do intestino médio. 
O capuz dorsal ( $\mathrm{dh}$ ) é grande, porém não apresenta área de triagem na parede esquerda. Na sua abertura existe, à esquerda, lobos do escudo gástrico (gs), e à direita, uma projeção bem desenvolvida do assoalho do estômago (p). Esta projeção, que DiNAMANI (1967) chamou de porção terminal da dobra axial, é muito mais desenvolvida ainda em $P$. perna chegando mesmo, como em $P$. viridis (DINAMANI 1967) a ultrapassar a abertura esofágica. Uma larga depressão, denominada bolsa esquerda (lp) localiza-se ventralmente ao escudo gástrico (gs). Ali se inicia um sulco ao longo do lado esquerdo sem formar, como em Lithophaga (PURCHON 1957), dois grupos de dutos. Nessa região, uma série de sulcos e dobras ciliadas (lpsa) irradia-se da abertura da bolsa esquerda (lp), como em Pinctata. No assoalho dessa região existe um trato de rejeição que envia partículas em direção ao início do sulco intestinal (ig').

O sulco intestinal (ig) tem origem na abertura da bolsa esquerda (lp) e se continua para o interior do ceco (c) no lado esquerdo e posterior da língua da tiflosole maior (ty'). Daí circunda o ápice da língua da tiflosole maior e encaminha-se em direção posterior, ao longo do lado anterior direito da tiflosole maior (ty), terminando no intestino médio $(\mathrm{mg})$.

Além dos dutos que se abrem na bolsa esquerda, o divertículo digestivo forma uma grande massa que está situada na região ântero-ventral do estômago e que não é dividida em lobos como PURCHON (1957) observou em Anadara Gray, 1847. Essa massa de divertículos abre-se no estômago por uma série de nove a dez dutos, localizados numa fileira transversa na parede ântero-ventral direita do estômago $\left(\mathrm{ddd}_{2}\right)$. Os orifícios desses dutos terminam na margem inferior de uma área lisa, que envolve o orifício esofágico.

Ao lado direito do estômago existe a área de triagem posterior (rpsa) e que não se estende, como em $P$. viridis (DINAMANI 1967), até o capuz dorsal (dh). Essa área em $P$. perna é limitada anteriormente por uma prega de rejeição ( $\mathrm{rg}$ ), descrita em vários Eulamellibranchiata, que retém partículas da área de triagem e as leva para o intestino médio $(\mathrm{mg})$.

\section{CONCLUSÕES}

Os espécimes de Perna perna vivem presos a substratos firmes, particularmente rochosos, na zona intertidal, alimentando-se de material em suspensão, apresentando adaptações a esse tipo de vida.

A espécie estudada pertence a família Mytilidae, apresentando assim características que os distinguem de outros bivalves.

$P$. perna vive em regiões desprotegidas com incidência de ondas, e não apresentam sifões verdadeiros, mas formações da dobra interna do manto, que é muscular. AVELAR \& NARCHI (1984) e WhITE (1937) descreveram o mesmo respectivamente para Brachidontes darwinianus darwinianus e Mytilus edulis. Algumas espécies cavadoras de Mytilidae apresentam animais com sifões longos como FANKBONER (1971) descreveu para Botula e Lithophaga. Entre os bivalves associados a P. perna, NARCHI $(1973,1975)$ descreveu respectivamente em Hiatella solida (Sowerby, 1834) e Petricola stellae Narchi, 1975 sifões longos, pois essas 
espécies vivem protegidas sob ascídias ou entre tubos de poliquetos. NARCHI \& DOMANESCHI (1993) ao estudarem Sphenia antillensis Dall \& Simpson, 1901, coletada presa entre fios de bisso de $P$. perna ou a algas, notaram que a espécie apresenta sifões curtos, apesar de serem encontradas também no mesmo ambiente das espécies anteriores.

A simplicidade dos sifões parece estar ligada também a vida em águas calmas (NARCHI 1972), que é o ambiente natural de Mytella charruana (NARCHI \& GALVÃo-BUENo 1983), mas não é o de $P$. perna, com sifões igualmente simples.

A grande sensibilidade dos sifões a movimentos bruscos e ao escurecimento repentino foi associada por OWEN (1953) e NARCHI (1972) à vida em águas calmas. Entretanto, essa sensibilidade ocorre em idêntico grau em $P$. perna. Também esse fato foi registrado por AVELAR \& NARCHI (1984) em Brachidontes darwinianus darwinianus vivendo no mesmo habitat que $P$. perna.

A presença de papilas tentaculares no sifão inalante de Mytella charruana foi considerada por NARCHI \& GALVÃO-BUENO (1983) como associadas à vida em praias lodosas, em águas com partículas em suspensão. No entanto elas ocorrem igualmente em P. perna, em Mytilus edulis (WHITE 1937) e em Brachidontes darwinianus darwinianus (AVELAR \& NARCHI 1984), todos de ambiente de águas batidas, com poucas partículas em suspensão. Limnoperna fortunei (Dunker, 1875), um Mytilacea de água doce, que vive em águas de correntes lentas, não apresenta nem mesmo papilas tentaculares nos seus sifões (MORTON 1973).

É provável então que pelo menos entre os Mytilidae o comprimento dos sifões, sua sensibilidade e a presença de papilas sejam mais características da família do que adaptações ao ambiente ou às partículas inaladas. Perna perna, que vive em águas agitadas, possui sifões sensíveis à trepidação e aos escurecimentos bruscos, e ainda papilas tentaculares. Se essas características fossem indicativas do tipo de ambiente, seria de se esperar que $P$. perna tivesse sifões pouco sensiveis e lisos.

A membrana sifonal, que separa o sifão inalante da cavidade do manto é, na espécie estudada, razoavelmente bem desenvolvida e bastante móvel. Quando inicialmente descrita por ORTON (1912) sua função foi dada como uma barreira entre o sifão inalante e os ctenídios, impedindo que a corrente inalante incidisse diretamente sobre estes, promovendo uma seleção mais efetiva de partículas. Esta função foi aceita por KELLOGG (1915) restringindo-a, porém, à presença de grande quantidade de partículas, ajudando na remoção de material de rejeição. Este autor relacionou, com vários exemplos, a presença dessa membrana sifonal com o canal de rejeição e chamou a atenção para espécies onde a membrana sifonal não é acompanhada pelo canal de rejeição: Cardium, Tivela crassateloides (Conrad, 1837), Mytilus californianus, sendo essa a condição constante nos Veneracea (NARCHI 1974a), como também o é nos Mytilidae. Por outro lado, em todos os exemplos citados, essa membrana é uma lâmina sem possibilidade de fechar a abertura interna dos sifões, como acontece em Venus ovata (Pennant, 1777) (ANSELL 1961), e também não deve ser interpretada como tendo a função de válvula.

A membrana sifonal foi correlacionada à vida em águas lodosas (YONGE 1948a), possivelmente com a função inicialmente sugerida por ORTON (1912) já citada. A correlação com o lodo é confirmada pelo estudo em Mytella charruana 
(NARCHI \& GALVÃo-Bueno 1983), mas não o é pelo estudo de $P$. perna, nem de outros mitilídeos de ambiente rochoso ou arenoso.

A musculatura em todos os mitilídeos segue um mesmo padrão estrutural. Há de se notar aqui a ausência do músculo adutor anterior em $P$. perna, característica do gênero, que é decorrente do ligamento bissal mais firme. O sucesso evolutivo dos Mytilacea pode ser atribuído ao alargamento posterior do animal e do desenvolvimento de sua condição heteromiária. Essa condição é uma conseqüência direta do desenvolvimento do ligamento bissal (YONGE 1976). Em P. perna esse desenvolvimento acabou por levar da condição heteromiária para a condição monomiária ao máximo da especialização à fixação a um substrato duro.

Também como decorrência da fixação bissal, houve uma adaptação da musculatura ligada ao bisso. Essa musculatura é desenvolvida em P. perna. O alongamento do músculo posterior retrator do bisso no sentido ântero-posterior segue a alteração da forma do corpo descrita por YONGE (1976).

Evidentemente, o bisso de $P$. perna é forte e desenvolvido, o que se justifica pela aderência à substratos firmes nesta espécie, enquanto que em Mytella charruana (NARCHI \& GALVÃO-BUENO 1983) que vive enterrada no lodo é menos desenvolvido. É interessante notar também a diferença na forma do sulco do bisso no pé das duas espécies. Enquanto que em Mytella charruana esse sulco é raso e simples, ele é muito mais profundo em $P$. perna e protegido, na sua borda, por uma bainha que, por aposição, forma um verdadeiro canal na superfície. Estas diferenças estruturais estão, sem dúvida, associadas ao ambiente onde as duas espécies vivem. Perna perna forma filamentos bissais em zona de arrebentação de ondas. Esta alta motilidade do meio ambiente torna difícil a formação dos filamentos bissais que devem, portanto, ser protegidos nesta fase. Daí o sulco ser mais profundo e sua superfície ser protegida pela bainha.

Os palpos mostram uma adaptação ao ambiente. Se bem que constituídos sobre um mesmo padrão estrutural, diferem em relação ao comprimento, sendo curtos em P. perna.

Quanto aos ctenídios, $P$. perna não apresenta cílios de guarda nos sulcos marginais. ATKINS (1936b) relaciona a presença desses cílios com a existência de uma grande quantidade de lodo na água, o que não acontece no ambiente onde $P$. perna se encontra.

Os cílios látero-frontais grandes em $P$. perna estão associados ao tamanho das partículas a serem selecionadas. Devido à movimentação causada pelas ondas, grãos de areia ficam em suspensão na água do mar e são freqüentes nos locais onde $P$. perna vive. Da mesma forma e pela mesma razão, os cílios laterais são também longos em P. perna.

Os discos ciliares são menores e em menor número em $P$. perna, possivelmente devido ao fato de que esta espécie filtre água com menos partículas em suspensão.

Ainda a superfície do manto colabora para a seleção de partículas na cavidade palial. Em P. perna os palpos são curtos, mas as áreas ciliadas são as mesmas que as descritas por NARCHI \& GALVÃo-BUENO (1983) em Mytella charruana. 
O estômago de $P$. perna corresponde ao tipo III da classificação de PURCHON (1957) e, pela localização posterior da bolsa esquerda, com dutos do divertículo digestivo abrindo-se nela e ao lado direito, no assoalho do estômago, fica enquadrado na Seção I da classificação de DiNAMANI (1967).

$\mathrm{O}$ estômago apresenta áreas de triagem bem desenvolvidas, do tipo $\mathrm{A}$ da classificação de REID (1965), um longo ceco digestivo, com seleção de partículas do tipo B, desta mesma classificação. Se a sistemática de PURCHON com base no estômago fosse reconhecida, a espécie aqui estudada estaria colocada na ordem Gastrotetartika da subclasse Polysyringia.

AGRADECIMENTOS. Nosso agradecimento ao Conselho Nacional de Desenvolvimento Científico e Tecnológico (CNPq), à Coordenação de Aperfeiçoamento de Pessoal de Ensino Superior (CAPES), pelas bolsas e auxílios concedidos, e à Georgeana Curi de Lima Meserani, pela colaboração na arte final dos desenhos.

\section{REFERÊNCIAS BIBLIOGRÁFICAS}

ABBud, L. 1969. Fisiologia e farmacologia dos músculos de Mytilus perna. Bolm. Fac. Filos. Ciên. Univ. S. Paulo 324. Zool. Biol. Mar. 26: 113-1180. Ageitos DE CASTEllanos, Z.J. 1957. Los mitilidos argentinos. Dep. Investigaciones Pesqueras (Minist. Agricult. \& Ganadería), Buenos Aires, p.1-12.

ANSELL, A.D. 1961. The functional morphology of the British species of Veneracea (Eulamellibranchia). J. Mar. biol. Ass. U.K 41 (2): 489-517.

ATKINS, D. 1936a. On the ciliary mechanisms and interrelationship of Lamellibranchs. Part I: New observations on sorting mechanisms. Quart. J. micr. Sci. 79: 181-308.

1936b. On the ciliary mechanisms and interralationship of Lamellibranchs. Part II: Sorting devices on the gills. Quart. J. micr. Sci. 79: 339-373.

. 1936c. On the ciliary mechanisms and interralationship of Lamellibranchs. Part III: Types of Lamellibranchs gills and their food currents. Quart. J. micr. Sci. 79: 375-421.

Avelar, W.E.P. \& W. NARCHI. 1984. Anatomia funcional de Brachidontes darwinianus darwinianus (d'Orbigny, 1846) -(Mollusca: Bivalvia). Pap. Avuls Depto. Zool., São Paulo, 35 (27): 331-359.

BARATTINI, L.P. \& E.H. URETA. 1961. La fauna de las costas uruguayas del Este (Invertebrados). Montevideo, Mus. Damaso Antonio Larrañaga. Cons. Dep. Montevideo, Uruguai, IV+195p.

BEAUPERTHUY, I. 1967a. Contribucion al conocimento de los mitilidos venezolanos (Mollusca: Bivalvia) (Abs). Lagena 14: 19.

—. 1967b. Los mitilidos de Venezuela (Moll. Bivalvia). Bolm. Inst. oceanogr., Cumana, 6: 7-115.

BEEDHAM, G.E. 1958. Observations on the mantle of Lamellibranchia. Quart. J. micr. Sci. 99 (2): 181-107. 
BERRY, P.F. 1978. Reprodution, growth and prodution in the mussel Perna Perna (L.), on the east coast of South África. Oc. Res. Inst. Invest. Rep. 48: 1-28.

BOUCART, C.; R.J. LAVALLARD \& P. LUBET. 1965. Ultrastructure du spermatozoide de la Moule (Mytilus perna von Ihering). C.R. Acad. Soc. Paris 260: 5096-5099.

Boutan, L. 1895. Recherches sur le byssus des Lamellibranche. Arch. Zool. exp. gén. 3: 297-338.

Carcelles, A.R. 1944. Catálogo de los Moluscos Marinhos de Puerto Quequén. Revta Mus. la Plata, Sér. Zool., 3: 233-309.

1950. Catálogo de los Moluscos Marinhos de la Patagônia. Anales Mus. Nahuel Huapi Perito 2: 41-100.

Carcelles, A.R. \& S.I. Williamson. 1951. Catálogo de los moluscos de la província Magellánica. Revta Inst. nac. Inves. Cienc. nat. Mus. argent. Ciênc. nat. Bernardino Rivadavia 2 (5): 223-383.

CARMO, T.M.S. \& J.E. LunETTA 1978. Changes in the lipid level of Perna perna (Linné, 1958) (Mollusca - Bivalvia), related to sex and sexual stages. Bolm. Fisiol. Animal, São Paulo, 2: 49-62.

DINAMANI, P. 1967. Variation in the stomach structure of the Bivalvia. Malacologia 5 (2): 225-268.

DionI, W. 1963. Consumo de oxigênio pelo mexilhão (Mytilus perna) do canal de São Sebastião. Ciênc. Cult., São Paulo, 15: 265-266.

EPIFANIO, R.M. 1967. Identification y descripcion de la larva veliconcha y dissoconcha del mejillon comestible Perna perna (L) del Oriente de Venezuela. Series Recursos y Explotacion Pesqueros 1 (3):95-113.

FANKBONER, P.V. 1971. The ciliary currents associated with feeding, digestion, and sediment removal in Adula (Botula) falcata Gould, 1851. Biol. Bull. 140: 28-45.

FERREIRA, J.F.; A.R.M MAGALHÃES; R.C. ROSAS \& J. GUZENSKI. 1990. Relatório das atividades desenvolvidas no Convênio ACAR PESC - UFSC para o cultivo de mexilhões. Florianópolis, SAAI, ACARPESC, UFSC, 43p.

Graham, A. 1949. The Molluscan stomach. Trans. roy. Soc. Edinb. 61 (3): 737-778.

HeBLING, N.J. 1976. The functional morphology of Anodontites trapezeus (Spix) and Anodontites trapesialis (Lamarck) (Bivalvia: Mycetopodidae). Bolm. Zool. Univ. São Paulo 1: 265-298.

HIROKI, K. 1977. On the resistance of isolated bivalve gill pieces to oxygen deficiency and hydrogen sulphide. Bolm. Fisiol. Animal Univ. S. Paulo 1: 9-20. IHERING, H. VON. 1900. On the south American Species of Mytilidade. Proc. malac. Soc. Lond. 4: 84-98.

KELLOGG, J.L. 1915. Ciliary mechanisms of Lamellibranchs with descriptions of anatomy. Jour. Morph. 26 (4): 625-701.

KLAPPENBACH, M.A. 1964. Lista preliminar de los Mytilidae brasileños con claves para su determinación y notas sobre su distribuicion. An. Acad. Bras. Ciênc. 37 (supl.): 327-352.

1965. Sobre las fechas de las especies de Mytilidae que describiera a 
d'Orbigny (Mollusca Pelecypoda). Neotropica 11 (36): 118-120.

LAMY, M.E. 1920. Notes sur les espéces de Mytilus décrites par Lamarck (fin). Bull.

Mus. Nat. d'Hist. Naturelle 26: 520-526.

LANGe De Morretes, F. 1949. Ensaio de catálogo dos moluscos do Brasil. Arch.

Mus. Paranaen., Curitiba, 7 (1): 5-216.

Lavallard, R.; G. Balas \& R. Schlenz. 1969. Contribuition à l'étude de la croissance relative chez Mytilus perna L.. Bolm. Fac. Fil. Ciên. Letr. Univ. São Paulo 324, Zool. Biol. Mar. (N.S.) 26: 19-31.

LUBET, P. 1973. Exposeé synoptique de donneés biologiques sur la moule Mytilus galloprovincialis (Lamarck, 1819) (Atlantique \& Meditérranée). Synopsis FAO Pêches 88: IV+40p.

LUNETTA, J.E. 1969. Fisiologia da reprodução de mexilhões (Mytilus perna) (Mollusca: Lamellibranchia). Bolm. Fac. Filos. Ciên. Letr. Univ. São Paulo, 324 Zool. Biol. Mar., (N.S.) 26: 33-111.

MAgalhães, A.R.M. 1985. Teor de proteínas do mexilhão Perna perna (Linné, 1758) (Mollusca: Bivalvia), em função do ciclo sexual. Dissertação de Mestrado, não publicada, Universidade de São Paulo, 177p.

MORTON, B. 1973. Some aspects of the biology and functional morphology of the organs of feeding and digestion of Limnoperna fortunei (Dunker) (Bivalvia: Mytilacea). Malacologia 12 (2): 265-281.

. 1987. The functional morphology of the organs of the mantle cavity of Perna viridis (Linnaeus, 1758) (Bivalvia: Mytilacea). American Malacological Bulletin 5 (2): 159-164.

MOORE, H.J. 1971. The structure of the latero-frontal cirri on the gills of certain lamellibranchs moluscs and their role in supension feeding. Marine Biology 11: 23-27.

NARCHI, W. 1972. Comparative study of the functional morphology of Anomalocardia brasiliana (Gmelin, 1791) and Tivela mactroides (Born, 1778) (Bivalvia, Veneridae). Bull. Mar.Sci. 22 (3): 643-670.

1974a. Aspectos ecológicos e adaptativos de alguns bivalves do litoral paulista. Pap. Avuls Depto. Zool., São Paulo, 27 (19): 235-262.

1974b. Functional Morphology of Petricola (Rupellaria) typica (Bivalvia, Petricolidae). Marine Biology 27: 123-129.

1975. Functional morphology of a new Petricola (Mollusca: Bivalvia), from the littoral of São Paulo. Brazil. Proc. mal. Soc. London 41: 451-465.

NARCHI, W. \& M.S. Galvão-Bueno. 1983. Anatomia funcional de Mytella charruana (d'Orbigny, 1846) (Bivalvia: Mytilidae). Bolm. Zool. Univ. S. Paulo 6: 113-145.

NARCHI, W. \& O. DomanesCHI. 1993. The functional anatomy of Sphenia antillensis Dall \& Simpson, 1901 (Bivalvia : Myidae). Jour. Moll. Stud. 59: 195-210.

ORTON, J.H. 1912. The mode of feeding of Crepidula, with an account of the current-producing mechanism in the mantle cavity, and some remarks on the mode of feeding in Gastropods and Lamellibranchs. Jour. Mar. biol. Ass. U.K. 
9 (3): 444-478.

OWEN, G. 1953 - On the biology of Glossus humanus (L.) (Isocardia cor Lam.). Jour. Mar. biol. Ass. U.K. 32: 85-106. 1974. Studies on the gill of Mytilus edulis: the eulatero-frontal cirri. Proc. Q. Soc. London 187: 83-91.

PUJOL, J.P. 1967. Formation of the byssus in the common mussel (Mytilus edulis L.). Nature 214: 204-205.

PURCHON, R.D. 1957. The stomach in the Filibranchia and Pseudolamellibranchia. Proc. Zool. Soc. London 129 (1): 27-59.

REID, R.G.B. 1965. The structure and function on the stomach in bivalve molluscs. Jour. Zool. 147: 156-184.

RIDEWOOD, W.G. 1903. On the structure of the gills of the Lamellibranchia. Phil. Trans. roy. Soc. Lond. 195: 147-284.

Rios, E. 1994. Seashells of Brazil. Rio, Grande, Editora FURG, 368p.

RoJAS, A.V. 1967. Observaciones experimentales sobre algunos aspectos biológicos del mejillón comestible (Perna perna Retzius). Lagena 14: 14.

ROJAS, A.V.\& E.R. MARTINEZ. 1967. Reproducción y desarollo larval esperimental del mejillón comestible de Venezuela, Perna perna (Linnaeus, 1758). Boln. Inst. Oceanogr., Cumana, 6: 266-284.

ROMERO, S.M.B. 1980. Características comportamentais e morfológicas dos estágios larvais de Perna perna (Lamellibranchia: Mytilidae) obtidos em laboratório. Bol. Fisiol. Animal Univ. São Paulo 4: 45-52.

SANTOS, E. 1955. Moluscos do Brasil (vida e costumes). Rio de Janeiro, F. Briquiet \& Cia, 134p.

SAlomÃo, L.C.; A.R.M. Magalhães \& J.E. LunetTA. 1980. Influência da salinidade na sobrevivência de Perna perna (Mollusca : Bivalvia). Bol. Fisiol. anim., Univ. São Paulo 4: 143-152.

SALOMÃo, L.C. \& J.E. LunETTA. 1989. The effects of salinity changes on the osmotic and ionic concentrations in the hemolymph of Perna perna (Mollusca: Bivalvia). Bol. Fisiol. anim. São Paulo 13: 29-38.

SAWAYA, P. 1965. Mitilicultura (Mytilus perna) no litoral do estado de São Paulo. Ciênc. Cult., São Paulo, 17: 312-313.

SAWAYA, P. \& L. ABBUD. 1963. Sobre a farmacologia dos músculos adutores do mexilhão (Mytilus perna). Ciênc. Cult., São Paulo, 15: 265.

SAWAyA, P. \& J. Khouri. 1963. A miogenia do coração de moluscos (Mytilus perna). Ciênc. Cult., São Paulo, 15: 279.

. 1965. The action of acetylcholine on the isolated heart of . Mytilus perna. Bolm. Fac. Filos. Ciên. Letr. Univ. São Paulo (Zool.) 25: 5-12.

Sawaya, P. \& C. Oliveira. 1965. Sobre as reações do coração de molusco lamelibranquio Mytilus perna à diferentes excitações. Ciênc. Cult., São Paulo, 17 (2): 268.

Siddall, S.E. 1980. A clarification of the genus Perna (Mytilidea). Bull. Mar. Sci. 30 (4): 858-870.

Soot-Ryen, T. 1955. A report on the family Mytilidae. Allan Hancock Pacif. 
Expd. 20 (1): 1-175.

STUCCHI-ZUCCHI, A. \& L.C. SALOMÃo. 1992. Effect of osmo-ionic concentration on the compound action potential of the cebebro-visceral connective of Perna perna (Mollusca, Bivalvia). Comp. Biochem. Physiol. 101 (1): 109-112.

TRUEMAN, E.R. 1950. Obervation on the ligament of Mytilus edulis. Quart. Jour. micr. Sci. 91 (3): 225-235.

UMIJI, S. 1969. Neurosecreção em Mytilus perna (Molusco Lamelibrânquio). Bolm. Fac. Filos. Ciên. Letr. Univ. São Paulo 324, Zool. Biol. Mar., (N.S.) 26: 181-254.

White, K.M. 1937 - Mytilus. Liverpool Memoires Biol. Comm. 7: 1-117.

YONGE, C.M. 1948a. Cleansing mechanisms and the function of the fourth pallial aperture in Spisula subtruncata (Da Costa) e Lutraria lutraria. (L.). Jour. Mar. biol. Ass. U.K. 27 (3): 585-596.

1948b. Formation of siphons in Lamellibranchia. Nature 1961: 198-199. 1953. The monomyarian condition in the Lamellibranchia. Trans. Royal. Soc. Edinb. 62 (12): 443-478.

1955. Adaptation to rock boring in Botula and Lithophaga (Lamellibranchia Mytilidae) with a discussion on the evolution of this habit. Quart. Jour. micr. Sci. 96 (3): 383-410. 151-171.

1957. Mantle fusion in Lamellibranchia. Pubbl. Staz. zool. Napoli. 29: 1976. The mussel: form and habit, p.1-12. In: B.L. BAYNE (Ed.). Marine Mussels: their Ecology and Physiology. Cambridge, Cambridge Univ. Press, 506p.

ZUIM, S.M.F. \& E.G. MENDES. 1980a. Tolerância de Perna perna e Brachidontes solisianus, a diferentes salinidades. Rev. Brasil. Biol., Rio de Janeiro, 40 (1): $137-41$.

1980b. Tolerância de dois mexilhões marinhos Perna perna e Brachidontes solisianus, a diferentes concentrações de um detergente aniônico. Revt. Brasil. Biol., Rio de Janeiro, 40 (3): 585-90.

1981. A influência da salinidade na taxa respiratória de dois mexilhões Perna perna e Brachidontes solisianus, (Mollusca, Bivalvia). Revt. Brasil. Biol., Rio de Janeiro, 41 (1): 57-61.

Recebido em 19.VII.1996; aceito em 16.IV.1997. 